\title{
Genetics of dark skin in mice
}

\author{
Karen R. Fitch, ${ }^{1}$ Kelly A. McGowan, ${ }^{1}$ Catherine D. van Raamsdonk, ${ }^{1}$ Helmut Fuchs, ${ }^{2}$ Daekee Lee, ${ }^{3}$ \\ Anne Puech, ${ }^{4}$ Yann Hérault, ${ }^{5}$ David W. Threadgill, ${ }^{3}$ Martin Hrabé de Angelis, ${ }^{2,7}$ \\ and Gregory S. Barsh ${ }^{1,6}$ \\ ${ }^{1}$ Departments of Pediatrics and Genetics, Stanford University School of Medicine, Stanford, California 94305, USA; \\ ${ }^{2}$ Institute of Experimental Genetics, GSF-National Research Center for Environment and Health, Neuherberg, D-85764, \\ Germany; ${ }^{3}$ Department of Genetics, Lineberger Cancer Center 11-129, University of North Carolina, Chapel Hill, North \\ Carolina 27599, USA; ${ }^{4}$ Centre National de Génotypage, 91057 Evry Cedex, France; ${ }^{5}$ Génétique Expérimentale et Moléculaire \\ Institut de Transgenose, 45071 Orleans CEDEX 2, France
}

Chemical mutagenesis in the mouse is a powerful approach for phenotype-driven genetics, but questions remain about the efficiency with which new mutations ascertained by their phenotype can be localized and identified, and that knowledge applied to a specific biological problem. During a global screen for dominant phenotypes in about 30,000 animals, a novel class of pigmentation mutants were identified by dark skin (Dsk). We determined the genetic map location, homozygous phenotype, and histology of 10 new Dsk and 2 new dark coat (Dcc) mutations, and identified mutations in Agouti (Met1Leu, Dcc4), Sox18 (Leu220ter, Dcc1), Keratin $2 e$ (Thr500Pro, Dsk2), and Egfr (Leu863Gln, Dsk5). Cutaneous effects of most Dsk mutations are limited to melanocytes, except for the Keratin $2 e$ and Egfr mutations, in which hyperkeratosis and epidermal thickening precede epidermal melanocytosis by 3-6 wk. The Dsk2 mutation is likely to impair intermediate filament assembly, leading to cytolysis of suprabasal keratinocytes and secondary hyperkeratosis and melanocytosis. The Dsk5 mutation causes increased tyrosine kinase activity and a decrease in steady-state receptor levels in vivo. The Dsk mutations represent genes or map locations not implicated previously in pigmentation, and delineate a developmental pathway in which mutations can be classified on the basis of body region, microscopic site, and timing of pigment accumulation.

[Keywords: ENU mutagenesis; epidermal growth factor receptor; melanocyte; pigmentation; skin development]

Received July 15, 2002; revised version accepted November 18, 2002.

Phenotype-driven genetics in model organisms is a powerful approach for dissecting molecular pathways relevant to human disease. In the mouse, specific pathways identified through studies of so-called "classical" mouse mutations such as limb deformity, microphthalmia, Splotch, or White spotting has provided momentum for large-scale chemical mutagenesis programs (Bedell et al. 1997; Justice et al. 1999; Balling 2001), intended to increase the number of genetic entry points for studying many different organ systems and physiologic processes (Hrabé de Angelis et al. 2000; Nolan et al. 2000; Shiroishi 2001).

The pigmentary system plays a prominent role in this endeavor. Melanocytes are nonessential cells in which small changes in gene expression are readily detected by simple visual inspection, and many of the developmental and physiologic pathways used by pigment cells have parallels in other less-accessible cell types such as germ cells or neurons (Silvers 1979; Jackson 1997). Model sys-

Corresponding authors.

${ }^{6}$ E-MAIL gbarsh@cmgm.stanford.edu; FAX (650) 723-1399.

${ }^{7}$ E-MAIL hrabe@gsf.de; FAX 089-3187-3500.

Article and publication are at http://www.genesdev.org/cgi/doi/10.1101/ gad.1023703. tems based on coat color have provided insight into rare disorders such as immunodeficiency and albinism in Chediak-Higashi syndrome, development of the enteric nervous system and piebaldism in Shah-Waardenburg syndrome, as well as for common human diseases like obesity or skin cancer (Jackson 1997; Spritz 1999).

Nearly all pigment mutations in mice have been identified by their effects on hair color, whereas only a few are known to alter skin color. In part, this difference is due to a bias in ascertainment; hair melanocytes are more numerous than skin melanocytes, with the latter confined mainly to nonhairy regions such as the footpads or tail (Quevedo and Holstein 1998). However, several considerations suggest that variation in mouse skin color is amenable to Mendelian genetics, and may offer the opportunity to model biological processes distinct from those surveyed by coat color mutations. Overexpression of hepatocyte growth factor (Kunisada et al. 2000) or Hras1 (Broome Powell et al. 1999) in transgenic mice causes dark skin, accumulation of dermal melanocytes, and increased susceptibility to melanoma, but genes that impinge on HGF or Ras signaling have not been identified as coat color mutations. In addition, a recently described recessive mutation, sooty foot, causes dark skin due to increased epidermal pigmentation (Budd 
et al. 1997); the gene mutated in sooty foot has not been identified, but is not allelic with previously known coat color mutations. Finally, most coat color mutations involve processes that act relatively early in development of the pigmentary system, in the case of white-spotting, or relatively late, in the case of defects in melanogenesis, melanosome biogenesis, or pigment type-switching (Silvers 1979). In contrast, changes in skin color depend on a different set of processes that occur after neural crest differentiation but before mature hair growth (see below).

Among three large-scale programs for chemical mutagenesis of the mouse genome carried out in England (Nolan et al. 2000), Germany (Hrabé de Angelis et al. 2000), or Japan (Shiroishi 2001), a significant proportion of phenodeviants show dark skin or hair; additional informative phenodeviants can be expected from current mutagenesis projects in the USA and Australia. Here, we describe a genetic, pathologic, and molecular characterization of 10 dark skin (Dsk) and 2 dark coat color (Dcc) mutants identified in the German screen. Among the Dsk mutations, we find one, Dsk2, which represents a new human disease model for ichthyosis bullosa of Siemens (IBS), a dominant keratin disorder, and another, Dsk5, which represents a novel gain-of-function allele in the epidermal growth factor receptor (Egfr) oncogene. The Dcc mutations are new alleles of "classical" loci, but the Dsk mutations map to locations in the genome not previously associated with pigmentation phenotypes, and identify distinct steps in a previously unappreciated developmental pathway. These results provide one of the larger molecular characterizations of a phenotype-driven chemical mutagenesis screen to date, and demonstrate how the genetics of dark skin can be used to investigate general mechanisms of mammalian development and disease.

\section{Results \\ Different effects of dermal versus epidermal pigment accumulation}

As skin appendages are formed late in gestation, a committed population of pigment cell precursors, melanoblasts, is found amid mesenchymal cells in the developing dermis; some of these melanoblasts remain in the dermis and differentiate into dermal melanocytes, whereas others migrate across the dermal-epidermal junction. Epidermal melanoblasts may differentiate into hair follicle melanocytes or extrafollicular skin melanocytes (Yoshida et al. 1996). Ultimately, each type of cell-dermal melanocyte, follicular melanocyte, and epidermal extrafollicular melanocyte-is distinct with regard to its morphology (Quevedo and Holstein 1998), pattern of cadherin expression (Nishimura et al. 1999; Jouneau et al. 2000), and competence to synthesize certain types of pigment (Silvers 1979). Thus, there are multiple developmental steps that, when perturbed, might cause changes in skin pigmentation (Fig. 1a; Yoshida et al. 2001).

The Dsk mutations described here were all identified by the presence of excess footpad pigmentation in heterozygous animals (Fig. 2a), but careful examination revealed unique aspects to the different lines. As shown in Figure 2 and summarized in Table 1, there are 2 broad phenotypic categories. Footpads from Dsk1, Dsk7, Dsk9, and Dsk10 (Class I, Fig. 2b) have excess pigment in a uniform and continuous slanted stripe that is especially a $\mathrm{E} 12$ - P10
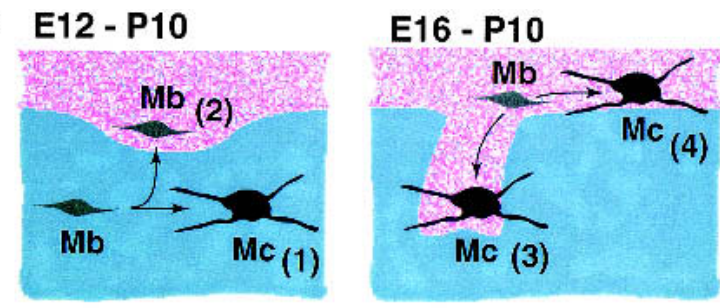

b

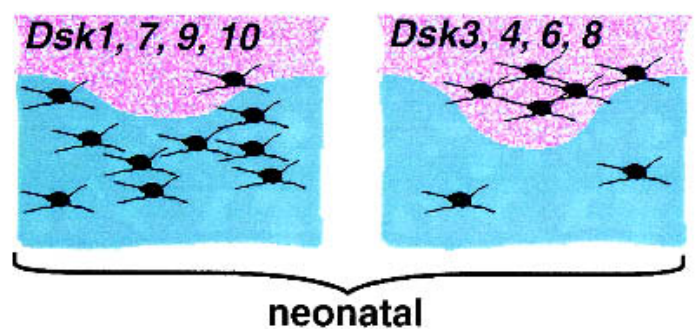

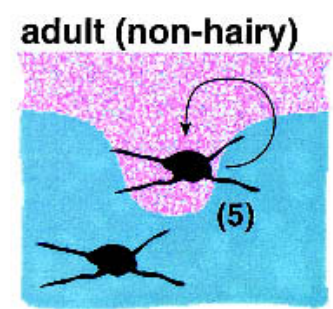

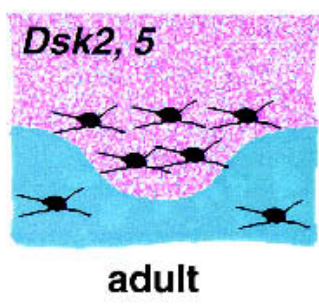

Figure 1. Developmental genetics of dark skin. (a) Between embryonic day 12 (E12) and postnatal day 10 (P10), neural crestderived melanoblasts $(\mathrm{Mb})$ migrate into the developing dermis (blue), and either differentiate into dermal melanocytes (Mc, 1) or continue migrating into the epidermis (pink, 2). Between E16 and P10, epidermal melanoblasts can differentiate into intrafollicular melanocytes that are responsible for adult hair color (3), differentiate into interfollicular melanocytes that are responsible for neonatal skin color but disappear by $2 \mathrm{wk}$ of age or in nonhairy regions of the skin and in the tail (4), differentiate into epidermal melanocytes that persist through adult life (5), and increase in number and/or activity in response to environmental signals such as UV irradiation (Rosdahl 1979) or wound healing (Hirobe 1988). Timing of these

stages is based on Quevedo and Holstein (1998) and Yoshida et al. (1996), and our own unpublished studies (C.D. van Raamsdonk and G.S. Barsh, unpubl.). (b) Dsk1, Dsk7, Dsk9, and Dsk10 cause an increase in dermal melanocytes (1); Dsk1, Dsk7, and Dsk10 also cause a slight darkening of hair (data not shown). Dsk3, Dsk4, Dsk6, and Dsk8 cause melanin to accumulate in nonhairy regions of the epidermis; the phenotype is apparent by 2-3 wk of age. Dsk2 and Dsk5 cause an increased number of epidermal melanocytes, but the phenotype is not apparent until 6-8 wk of age. 
Fitch et al.
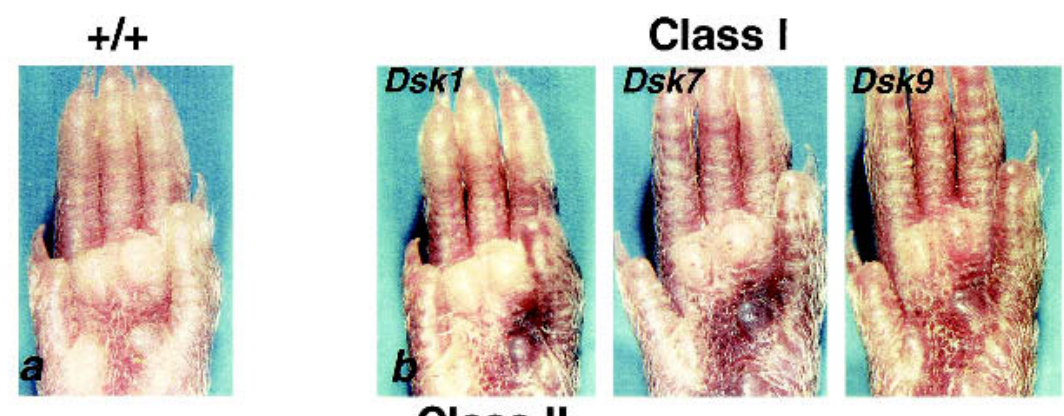

Class II
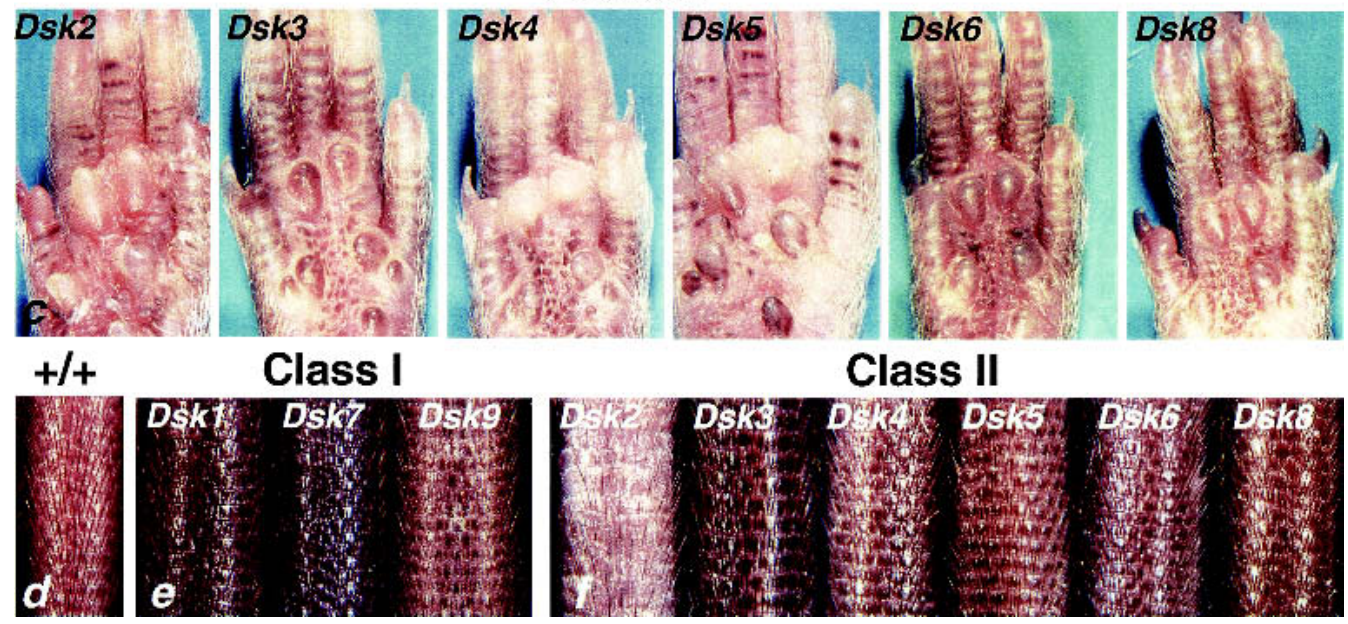

Class I
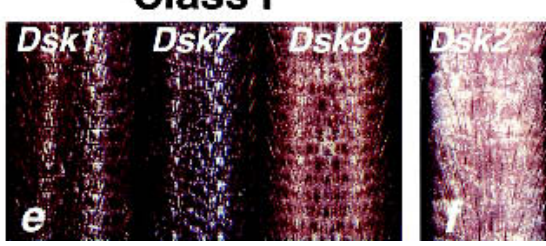

\section{Class II}

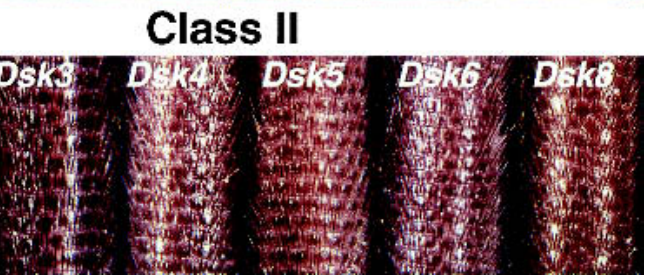

Figure 2. Footpad and tail phenotype of Dsk1-Dsk9. At 4 wk of age, footpads from C3HeB/FeJ nonmutant mice $(a)$ have little or no pigment, whereas footpads from Dsk1,Dsk7, and Dsk9 (b) exhibit a continuous bluish-gray stripe. Footpads from Dsk2, Dsk3, Dsk4, Dsk5, Dsk6, and Dsk8 (c) exhibit punctate accumulation of pigment with a brown hue on the volar pads, intervolar scales, and phalangeal ridges. (The footpad images for Dsk2 and Dsk5 are from animals 3 and 5 mo of age, respectively.) The footpad patterns fall into two broad categories that correlate with the microscopic site of pigment accumulation in the dermis (Class I) or epidermis (Class II); however, the tail phenotypes $(d-f)$ are more variable. Tails of $D s k 1$ and $D s k 7(e)$ are extremely dark in both the scales and interscale regions; tails of $D s k 3(f)$ are extremely dark but only within the scales; tails of $D s k 4, D s k 6$, and $D s k 8$ are moderately dark and can be easily distinguished from nonmutant littermates; and Dsk5 and Dsk9 show little or no excess tail pigmentation. In Dsk2, hyperkeratosis and intraepidermal cytolysis (Fig. 4, below) cause an overall scaly appearance.

prominent over the volar pad at the base of the first digit (but not other volar pads) and has a bluish-gray color. In contrast, footpads from Dsk2, Dsk3, Dsk4, Dsk5, Dsk6, and Dsk8 (Class II, Fig. 2c) have excess pigment with a brown hue distributed in small punctate patches on most or all of the volar pads. In addition, excess pigment in the Class II mutants is found on phalangeal ridges and intervolar pad scales; structures with an epidermal component normally subject to high levels of friction.

The distinction between broad phenotypic classes on the basis of footpad pigmentation extends to other regions of the body (Table 1). In particular, Dsk1, Dsk7, and Dsk10 (class I mutants) are darker than most of the other mutants in ear and tail skin (Fig. 2e; data not shown), and, unlike the other mutants, cause a slight darkening of hair in addition to skin (data not shown). The developmental basis for the class I phenotype became apparent upon histologic examination of skin from mutant animals, which revealed normal patterns of pigment deposition in the epidermis, but a dramatic accumulation in the dermis (Fig. 3). Increased dermal pigment in Dsk1, Dsk7, and Dsk10 is apparent by 2-3 d of age, progresses through weaning, and gradually diminishes in older animals. This suggests that the decision of dermal melanoblasts to differentiate in situ or migrate across a basement membrane, which normally takes place between E12.5 and P10, is perturbed by Dsk1 and Dsk7, but has a very similar phenotype (Table 1); its map position (see below) overlaps with that of Dsk1; thus, all three mutations, Dsk1, Dsk7, and Dsk10 are likely to affect the same underlying process.

The class II Dsk mutants, grouped on the basis of their footpad phenotypes, show more heterogeneity in other body regions than the class I mutants. For example, Dsk2 mutant tails are scaly, Dsk3 mutant tails are dark, and tails from the other class II mutants are mildly affected or normal. Nonetheless, the class II mutants share a common histologic phenotype that is opposite to that of class I, with little or no excess pigment in the dermis, but a dramatic accumulation in the epidermis (Fig. 3). Increased pigmentation in the class II mutants also has a later onset than in most of the class I mutants. Dsk3, Dsk4, Dsk6, and Dsk8 (class II) are evident at weaning, whereas Dsk2 and Dsk5 (class II) are not apparent until 
Table 1. Phenotypic, genetic, and molecular characteristics of dark skin and dark coat mutations

\begin{tabular}{|c|c|c|c|c|c|c|c|c|c|}
\hline \multirow[b]{2}{*}{ Locus } & \multicolumn{7}{|c|}{ Phenotype } & \multirow{2}{*}{$\begin{array}{c}\text { Map } \\
\text { position }^{\mathrm{a}}\end{array}$} & \multirow[b]{2}{*}{ Molecular ${ }^{\mathrm{b}}$} \\
\hline & Feet $^{\mathrm{c}}$ & Tailc & Ears $^{c}$ & Timing $^{\mathrm{d}}$ & Other $^{\mathrm{d}}$ & Histology $^{\mathrm{d}}$ & Homozygote & & \\
\hline Dsk1 & +++ & +++ & +++ & $3 d_{\text {; fades with age }}$ & $\begin{array}{l}\text { dark hair and } \\
\text { hairbearing skin }\end{array}$ & Dermal & $\begin{array}{l}\text { darker than } \\
\text { heterozygote }\end{array}$ & $19(9)$ & - \\
\hline Dsk2 & ++ & ++ & ++ & $\begin{array}{l}6 \text { wk; darkens with } \\
\text { age }\end{array}$ & $\begin{array}{l}\text { flaky tail, feet and } \\
\text { ears }\end{array}$ & Epidermal & $\begin{array}{l}\text { similar to } \\
\text { heterozygote }\end{array}$ & $15(58)$ & $\begin{array}{l}\text { Keratin 2e: } \\
\text { Thr500Pro }\end{array}$ \\
\hline Dsk3 & ++ & +++ & ++ & $\begin{array}{l}2 \text { wk; darkens with } \\
\text { age }\end{array}$ & small size & Epidermal & embryonic lethal & $7(6)$ & - \\
\hline Dsk4 & ++ & ++ & + & $\begin{array}{l}2 \text { wk; darkens with } \\
\text { age }\end{array}$ & none & Epidermal & embryonic lethal & $4(1)$ & - \\
\hline Dsk5 & ++ & + & + & $\begin{array}{l}8-12 \text { wk; darkens } \\
\text { with age }\end{array}$ & wavy hair; long nails & Epidermal & $\begin{array}{l}\text { similar to } \\
\text { heterozygote }\end{array}$ & $11(9)$ & Egfr: Leu863Gln \\
\hline Dsk6 & + & ++ & + & $\begin{array}{l}3 \text { wk; darkens with } \\
\text { age }\end{array}$ & small size; dark nails & Epidermal & embryonic lethal & $3(66)$ & - \\
\hline Dsk7 & +++ & +++ & +++ & $\begin{array}{l}3 \mathrm{~d} \text {; fades slightly } \\
\text { with age }\end{array}$ & $\begin{array}{l}\text { dark hair and } \\
\text { hairbearing skin }\end{array}$ & Dermal & $\begin{array}{l}\text { darker }{ }^{\mathrm{e}} \text { than } \\
\text { heterozygote }\end{array}$ & $10(42)$ & - \\
\hline Dsk8 & + & ++ & + & $\begin{array}{l}3 \text { wk; darkens with } \\
\text { age }\end{array}$ & small size; dark nails & Epidermal & embryonic lethal & $3(66)$ & - \\
\hline Dsk9 & + & + & + & $\begin{array}{l}3 \text { wk; fades slightly } \\
\text { with age }\end{array}$ & dark perineum & Dermal & embryonic lethal & $11(46)$ & - \\
\hline Dsk10 & +++ & +++ & +++ & $3 \mathrm{~d}$; fades with age & dark hair & Dermal & $\begin{array}{l}\text { darker than } \\
\text { heterozygote }\end{array}$ & $19(15)$ & - \\
\hline$D c c 1$ & NA & NA & NA & $2 \mathrm{wk}$ & sparse hair & NA & small size; sparse hair & $2(95)$ & Sox18: Leu220Stop \\
\hline Dcc4 & NA & NA & NA & $2 \mathrm{wk}$ & none & NA & dark hair & $2(90)$ & Agouti: Met1Leu \\
\hline
\end{tabular}

${ }^{a}$ Map position is given as the chromosome location followed, in parentheses, by the position in centiMorgans from the centromere; flanking markers (1-5 $\mathrm{cM})$ are given in Materials and methods.

bMolecular abnormalities were identified for Dsk2, Dsk5, Dcc1, and Dcc4, as described in Results.

'The extent of skin darkening apparent from gross inspection of 3-4 week-old animals was graded as slightly darker than nonmutant $(+)$, moderately dark $(++)$, or extremely dark $(+++)$.

${ }^{\mathrm{d}}$ We describe each mutant according to when visible darkening is first evident, whether or not darkening increases or fades with age, if other body regions are visibly affected, and the microscopic site at which pigment accumulates in the footpads of 4-6-week-old animals. Classification of pigment accumulation as dermal or epidermal is based on examination of hematoxylin and eosin-stained sections from multiple animals for each line; representative photomicrographs are displayed in Figure 3.

${ }^{\mathrm{e}} D s k 7$ homozygotes exhibit a large increase in dermal pigmentation and a slight increase in epidermal pigmentation.

${ }^{\mathrm{f}} D s k 1-D s k 9$ were characterized at Stanford; Dsk10 was characterized initially at Institut de Transgenose. Comparison of their features suggests that Dsk10 is a class I mutation (Fig. 2) very similar to Dsk1 and Dsk7.

6-12 wk of age. Hyperpigmentation in all of the class II mutants also becomes more severe with age, which suggests that one or more of the class II mutants affects the decision of epidermal melanoblasts to proliferate and/or differentiate in situ (Fig. 1a).

\section{Genetic map locations and homozygous phenotypes of Dsk mutants}

Establishing the genetic map location for each Dsk mutant allowed us to investigate allelism to each other or previously existing mutations, to determine the homozygous phenotype, and to identify potential candidate genes. We used a panel of 60 SSLP markers to scan 16-40 $(\mathrm{C} 3 \mathrm{HeB} / \mathrm{Fe} J-\mathrm{Dsk} /+\times \mathrm{C} 57 \mathrm{BL} / 6 \mathrm{~J}) \mathrm{F} 1 \times \mathrm{C} 3 \mathrm{H}$ back-cross progeny for each of the Dsk mutants, and subsequently narrowed each location to a small interval by use of additional markers and additional back-cross progeny (Table 1).

The 10 Dsk mutants map to 8 different locations; all are distinct from previously existing coat color mutations (Table 1). Dsk6 and Dsk8 map to the same interval and exhibit very similar phenotypes, as do Dsk1 and Dsk10; thus, even in this relatively small collection, there is evidence for multiple alleles per gene. With the exception of Dsk2 and Dsk5 (see below), the map locations do not immediately suggest positional candidates, but do provide a means for unambiguous determination of homozygous phenotypes.

Homozygotes for three of the class I mutants, Dsk1, Dsk7, and Dsk10, show abnormalities qualitatively similar but quantitatively more severe than the heterozygotes, with increased accumulation of dermal pigment in the ears, tail, and footpads, as well as in hairy skin (data not shown). In contrast, homozygotes for Dsk3, Dsk4, Dsk6, Dsk8, and Dsk9 die prior to birth. Thus, some processes affected by Dsk mutations are limited to the skin, whereas others are required for embryonic viability.

\section{Melanocytosis in a model for a human keratin disorder}

Tail, footpad, and ear skin in Dsk2 mutant animals is not only dark but also scaly (Fig. 2). Both pigmentation and scaling phenotypes are apparent, and similar in quality, in heterozygotes compared with homozygotes. However, scaling is evident by $3-4 \mathrm{wk}$ of age (Fig. $4 \mathrm{a}, \mathrm{b}$ ), whereas pigment accumulation does not appear until 3-6 wk 


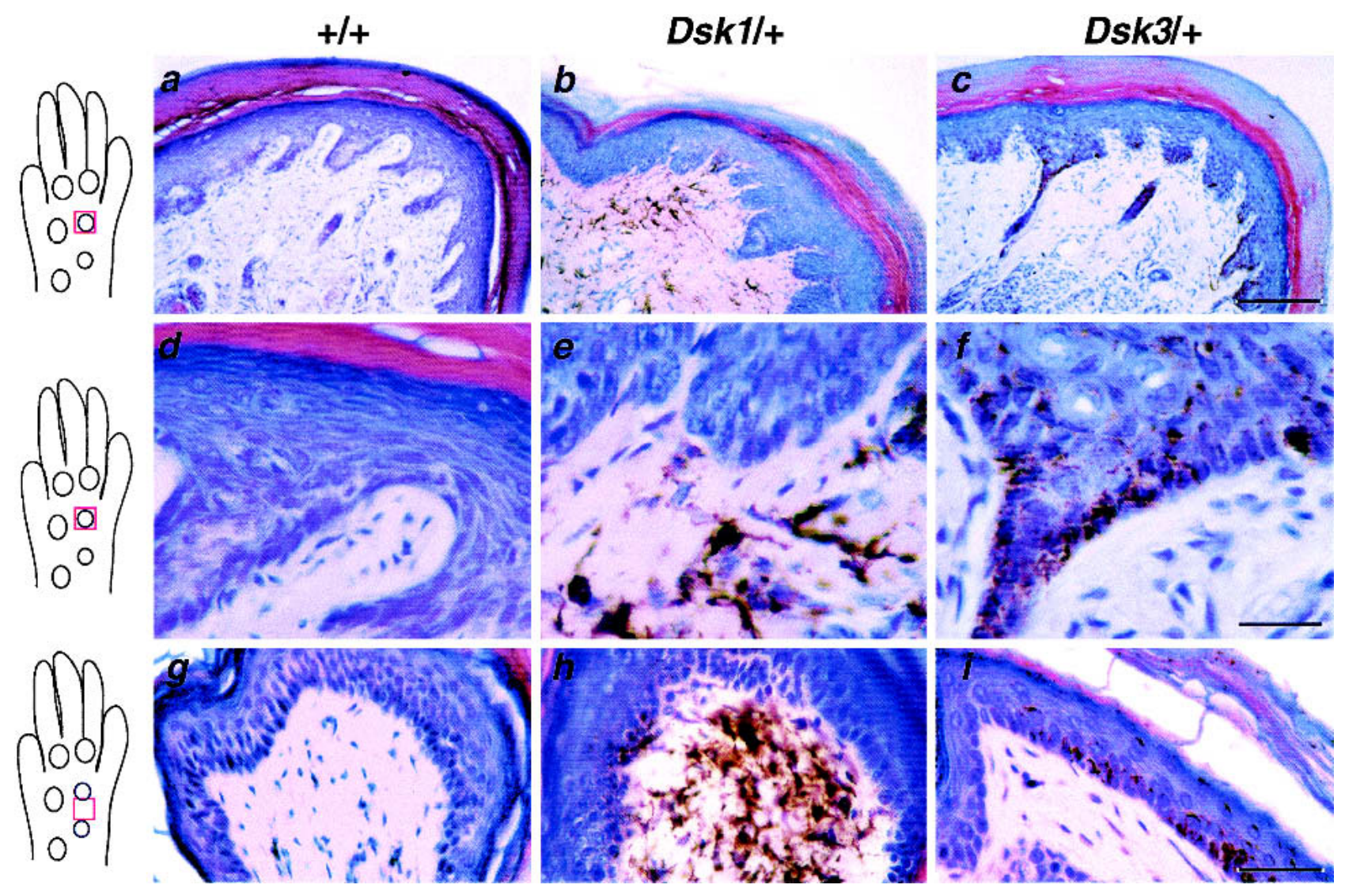

Figure 3. Histologic site of pigment accumulation in representative dark skin mutants. Footpad sections from 4 -week-old C3HeB/FeJ nonmutant $(a, d, g), D s k 1(b, e, h)$, and Dsk3 $(c, f, i)$ animals. Drawings at left depict the location of the sections; volar pads $(a-f)$ or intervolar scales $(g-i)$. Dermal accumulation of pigment shown for Dsk1 is similar to that which occurs in Dsk7, Dsk9, and Dsk10; epidermal accumulation of pigment shown for $D s k 3$ is similar to that which occurs in $D s k 4, D s k 6$, and $D s k 8$. Bars: $a-c, 100 \mu m ; d-f$, $25 \mu \mathrm{m}$.

later (Fig. 4c,d,e), suggesting that excess pigment deposition is secondary to a keratinocyte defect.

Histologically, Dsk2 footpads at 1 mo of age (Fig. 4a,b) and tails (data not shown) exhibit a thickened epidermis and cytolysis in the upper spinous and granular layers. By 2 mo of age, excess pigment in Dsk2 mutant skin is found throughout epidermal keratinocytes in a typical perinuclear distribution but at greatly increased levels compared with normal (Fig. 4c,d,e). To determine whether excess pigmentation was caused by an increase in melanocyte number, we made use of a transgenic reporter, Tg.DctLacZ (Mackenzie et al. 1997), whose expression in the epidermis is confined to pigment cells. Compared with footpads of nonmutant littermates, which had few or no lacZ-positive cells at 2 mo of age (Fig. 4c), footpads of Dsk2/+; Tg.DctLacZ mice showed increased numbers of melanocytes in areas that coincided with increased epidermal melanin (Fig. 4d,e).

The Dsk2 histologic phenotype is reminiscent of dominant keratin disorders caused by point mutations that disrupt intermediate filament assembly, and the 5-cM interval to which we mapped Dsk2, D15Mit42D15Mit246, includes the basic keratin complex. Among a minimum of 10 keratin genes in this complex, we con- sidered keratin 1 (Krt1) and Keratin $2 e$ (Krt2e) as the most likely candidates, because they are expressed specifically in the suprabasal epidermis and because missense mutations cause epidermal thickening and suprabasal blistering in the human diseases epidermolytic hyperkeratosis (KRT1) and ichthyosis bullosa of Siemens (KRT2E; Fuchs 1996; Arin and Roop 2001).

Using PCR amplification from genomic DNA of Dsk2 homozygotes, protein-coding regions of Krt1 were normal, but in Krt2e, we identified a missense mutation that predicts a Thr500Pro substitution in the rod 2B domain, a region known to be important for keratin-keratin interactions (Fig. 4f). Remarkably, the same amino acid substitution was reported in a patient with ichthyosis bullosa of Siemens (Yang et al. 1997), a dominant disorder characterized by the presence of widespread blistering at birth with later development of flexural hyperkeratoses (Traupe et al. 1986; Steijlen et al. 1990). Skin abnormalities in Dsk2 mutants are confined to the tails, ears, and footpads, and we have never observed blistering in mutant animals; however, the intra-epidermal level at which cytolysis occurs in Dsk2 mutant skin is nearly identical to that which occurs in ichthyosis bullosa of Siemens. These observations suggest that Keratin 

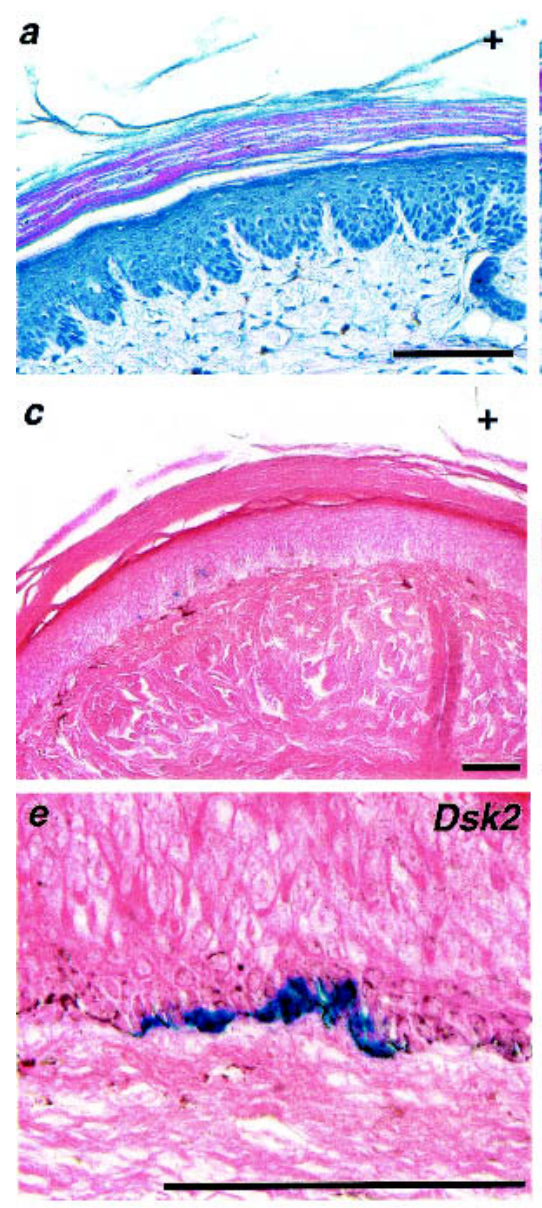
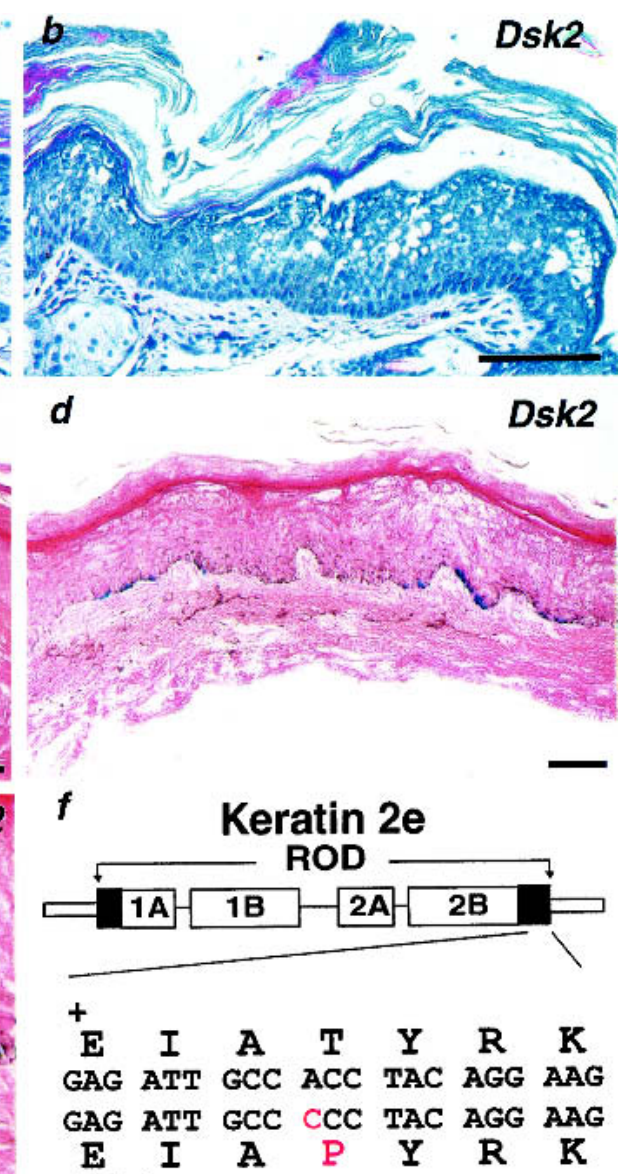

(500)
Figure 4. Histologic and molecular characterization of Dsk2. $(a, b)$ Hematoxylin and eosin-stained footpad sections from 1-month-old $\mathrm{C} 3 \mathrm{HeB} / \mathrm{FeJ}$ nonmutant $(a)$ and Dsk2/+ (b) littermates. Dsk2 mutant footpads have a thickened epidermis and exhibit cytolysis in suprabasal layers. $(c-e)$ Xgal- and eosin-stained footpad sections from 2-month-old nonmutant $(c)$ and Dsk2/+ $(d, e)$ animals that carry the Dct$L a c Z$ reporter transgene. Dsk2 mutants show increased numbers of epidermal melanocytes that correlate with sites of excess pigment deposition. (f) An A-to-C transversion in genomic DNA of Dsk2 animals predicts a Thr-to-Pro substitution in the rod 2B domain of Krt2e. The exact same amino acid change has been described in a patient with ichthyosis bullosa of Siemens (Yang et al. 1997). Bars, $50 \mu \mathrm{m}$.
$2 \mathrm{e}$ is specialized for the upper spinous layer of the epidermis in both humans and mice, but that the body regions and developmental times at which specialization is required differ between species (Herzog et al. 1994; Smith et al. 1999).

\section{A hypermorphic mutation in the Egfr}

Like Dsk2, excess footpad pigmentation in Dsk5 mutant animals becomes apparent only in adult animals and progresses with age. The pigmentary effects of Dsk 5 are restricted to the footpads; in addition, some Dsk5 mutant animals show increased nail length (Fig. 5c). Histologically, the epidermis in Dsk5 skin is thickened, with a pattern of excess pigment deposition and an increased number of melanocytes in the epidermis similar to Dsk2 (Fig. 5d). Also, like Dsk2, hyperkeratosis occurs before pigment accumulation; at 1 mo of age, Dsk5/+ skin is mildy thickened compared with $+/+$ skin, at 2 mo of age, Dsk5/+ skin shows increased thickening and mild hyperpigmentation, and by 6 mo of age, Dsk5/+ skin exhibits obvious pigment accumulation and melanocytosis (Fig. $5 e-\mathrm{j})$.

We mapped Dsk5 to a 10-cM interval, D11Mit2D11Mit294, which includes the epidermal growth factor receptor $(E g f r)$ gene. Disturbances in Egfr signaling have not been associated previously with pigmentary abnormalities, but are well known to cause defects of hair follicle architecture in animals homozygous for the Tgfa ${ }^{\text {wa1 }}$ or Egfr ${ }^{\text {wa2 }}$ mutations (Mann et al. 1993; Luetteke et al. 1994), and close inspection of Dsk5 mutant animals revealed a wavy coat in 3-week-old animals that became less apparent with age. In PCR-amplified liver cDNA from Dsk5 homozygotes, we identified a missense mutation that predicts a Leu863Gln substitution; this site lies within the tyrosine kinase domain and is conserved among all mammalian Egfr family members (Erbb2, Erbb3, and Erbb4), as well as distantly related receptor tyrosine kinases c-abl, c-src, the Drosophila homolog Torpedo, and the Caenorhabditis elegans homo$\log$ Let-23 (Fig. 6a). On the basis of the recently reported crystal structure of the human Egfr kinase domain (Stamos et al. 2002), the Leu863Gln substitution lies within a three-residue $\beta$-strand that helps to stabilize the activation loop, an extended surface feature characteristic of all tyrosine kinases that interacts with both the catalytic site and the ATP-binding site (Fig. 6b).

Some effects of Egfr on the skin are thought to represent paracrine or autocrine activity within keratinocytes; however, Egfr expression has also been reported in cultured melanocytes (Gordon-Thomson et al. 2001) and in melanoma cells (Mattei et al. 1994). To compare 
Fitch et al.

Figure 5. Histologic characterization of Dsk5. $(a-d)$ Footpad sections from 6month-old nonmutant $(a, b)$ and Dsk5/+ littermates carrying the $\operatorname{Dct} L a c Z$ reporter transgene $(c, d)$ were stained with Xgal and eosin $(b, d)$. The mutant footpad exhibits increased pigmentation on the volar pads, epidermal thickening, and deepening of the rete pegs. Comparison of hematoxylin and eosin-stained footpad sections from mates at 1,2 , and 6 mo of age $(e-j)$ shows that epidermal thickening develops by $1-2$ mo of age, whereas hyperpigmentation does not develop until 2 mo of age. Bars, $50 \mu \mathrm{m}$. isogenic nonmutant and Dsk5/+ litter-
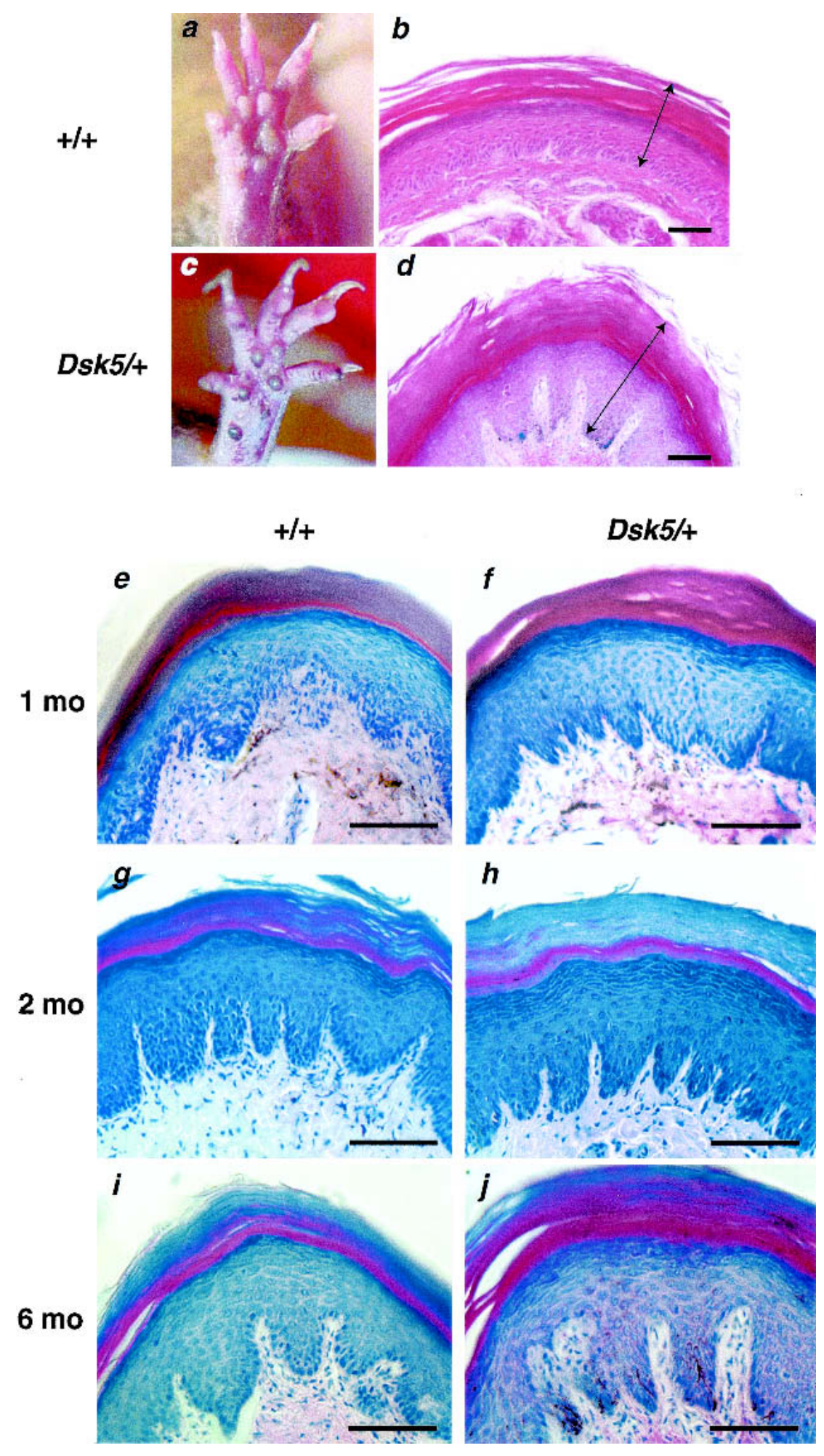

the relative levels of Egfr expression in melanocytes and keratinocytes, we examined skin sections from Tg.DctLacZ/+ animals doubly stained with Xgal and an Egfr antibody. In the footpads (Fig. 7a) and tail (data not shown), there is strong immunostaining for Egfr throughout all keratinocyte layers, but no obvious immunostaining of melanocytes. Taken together with the observation that hyperkeratosis becomes apparent 3-4 wk before pigment accumulation, these findings suggest that epidermal melanocytosis caused by Dsk5 is not a direct response of altered Egfr signaling, but, instead, is secondary to increased keratinocyte proliferation and epidermal thickening.

Previously described alleles of the endogenous Egfr 
a

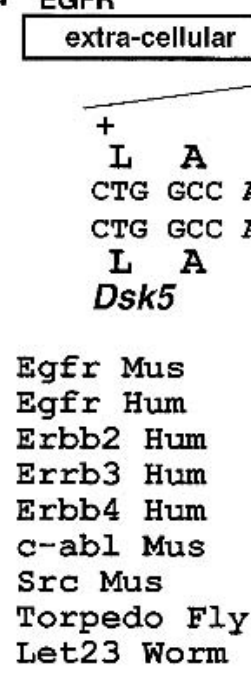

$b$

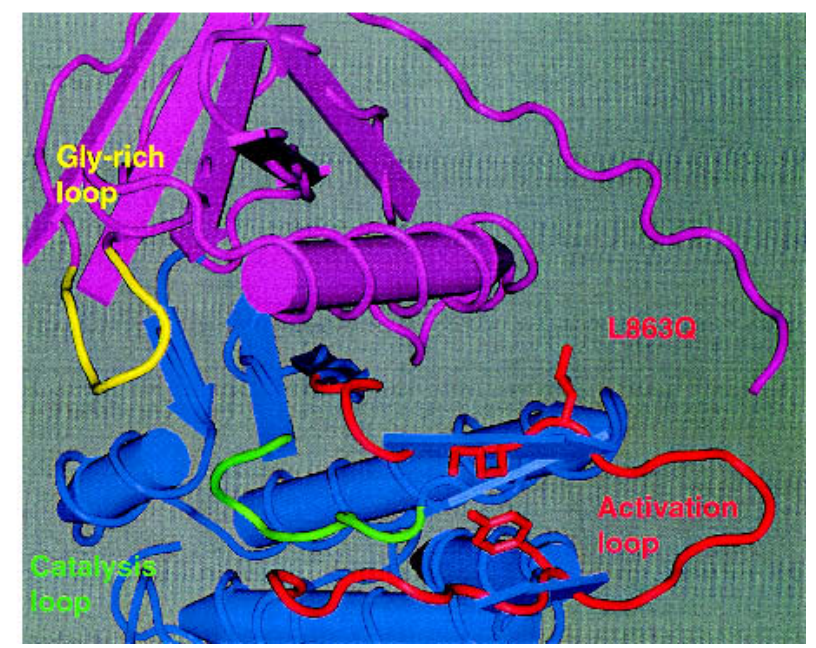

Figure 6. An Egfr mutation in Dsk5. (a) A T-to-A transversion in genomic DNA of Dsk5 animals predicts a Leu-to-Gln substitution in the kinase domain of Egfr. Numbering is based on the full-length mouse precursor protein. Leu 863 is highly conserved in all Erbb family members, as well as more distantly related receptor tyrosine kinases such as c-abl, Src, Torpedo (Drosophila), and Let 23 (C. elegans). (b) Position of the Leu863Gln substitution mapped onto the three-dimensional structure of the human Egfr tyrosine kinase domain; Leu 863 corresponds to Leu 837 in the scheme of Stamos and Eigenbrot (Stamos et al. 2002). The N-and C-terminal domains are colored pink and blue, respectively, and key regions for kinase function are colored yellow, green, and red as indicated. Side chains are indicated for Lys 862, Leu 863, and Tyr 871; $\beta$-strand hydrogen bond interactions from Lys 862 to Leu 864 and hydrophobic interactions between Lys 862 and Tyr 871 play key roles in maintaining the conformation of the activation loop (Stamos et al. 2002). Coordinates are from PDB 1M14, and are displayed with Cn3D.

gene all cause a loss-of-function, with phenotypic manifestations either limited to homozygotes or, in the case of a dominant negative mutation, causing homozygous lethality (Luetteke et al. 1994; Threadgill et al. 1995; Thaung et al. 2002). Dsk5 differs from these loss-of-function mutations in several respects. Homozygotes for Dsk5 are viable and fertile, with cutaneous phenotypes similar to heterozygous animals, and Egfr loss-of-function alleles cause a thinning of the epidermis, whereas the Dsk5 mutant animals display a thickened epidermis. Hyperkeratosis and epidermal thickening has also been described in animals that carry a Tgfa transgene driven by the keratin 14 promoter, and, therefore, might be explained by Egfr gain-of-function, as Tgfa is an Egfr ligand (Vassar and Fuchs 1991). To investigate genetically whether Dsk5 represented a loss- or gain-of-function mutation, we examined progeny of a $D s k 5 /+\times E g f r^{\mathrm{wa2}} /+$ cross. The Egfr ${ }^{\text {wa2 }}$ allele is hypomorphic; it is caused by a missense substitution in the kinase domain that does not affect protein levels but severely impairs ligand-induced Egfr signaling (Luetteke et al. 1994; Fowler et al. 1995). We reasoned that if Dsk5 represents a loss-offunction, then a hypomorph such as Egfr wa2 would enhance the mutant phenotype, but if Dsk5 represents a gain-of-function, then a hypomorph would rescue or ameliorate the mutant phenotype. We examined 14 Dsk5/Egfr ${ }^{\text {wa2 }}$ and 18 Dsk5/+ animals in a consistent genetic background at 3-12 mo of age; in every case, footpad pigmentation of Dsk5/Egfr ${ }^{\text {wa2 }}$ animals was lighter than their Dsk5/+ littermates (Fig. 7b,c,d). Amelioration of the Dsk5 mutant phenotype by Egfr ${ }^{\text {wa2 }}$ indicates that
Dsk5 is hypermorphic, and suggests that the Leu863Gln alteration causes increased Egfr signaling.

To determine the effect of the Dsk5 mutation on Egfr activity, we examined levels of protein and mRNA expression, and measured ligand-induced autophosphorylation in liver extracts, in which endogenous levels of Egfr can be detected easily by immunoblotting. We found that Dsk5 caused a dose-dependent decrease in Egfr protein; liver extracts from Dsk5/+ animals contain $\sim 50 \%$ of the normal amount, whereas extracts from homozygous mutants are reduced by $\sim 90 \%$ (Fig. 7 e). In contrast, Dsk 5 has no detectable effect on Egfr mRNA levels (Fig. 7f), which suggests that the Leu863Gln alteration either impairs protein translation or causes increased receptor turnover (Felder et al. 1992). Using an antiphosphotyrosine antibody to probe immunoblots of liver extracts, basal levels of phosphorylated Egfr were undetectable in +/+, Dsk5/+, and Dsk5/Dsk5 mutant animals (Fig. $7 \mathrm{~g}, \mathrm{~h}$ ). However, subcutaneous administration of Egf induced a rapid increase in levels of phosphorylated Egfr that were similar in +/+ and Dsk5/+ animals, and slightly reduced in Dsk5/Dsk5 animals (Fig. $7 \mathrm{~g}, \mathrm{~h}$ ). Thus, Dsk5 causes an increase in the proportion of Egfr that becomes phosphorylated in response to ligand. We also examined the response of phosphorylated and total Egfr levels in Dsk5/+ and +/+ mice to different levels of Egf, and to pretreatment with a phosphatase inhibitor (data not shown), and observed no differences between mutant and nonmutant animals other than the relative increase in phosphorylation. Finally, we expressed the normal and Leu863Gln mutant Egfr in cultured cells and com- 
Fitch et al.
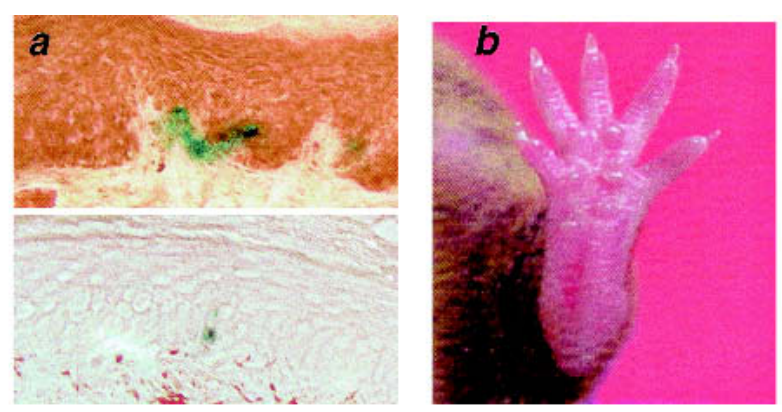

$+/+$

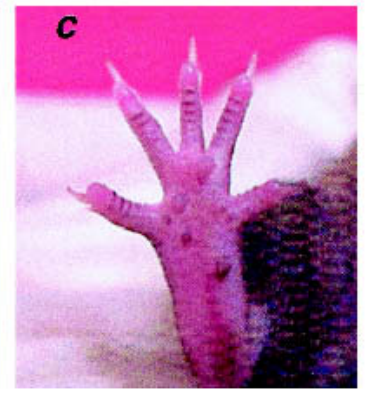

Dsk5/+

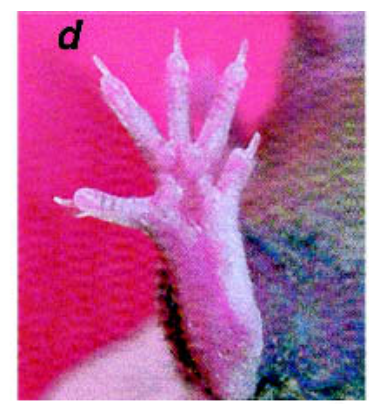

Dsk5/Egfrwa2

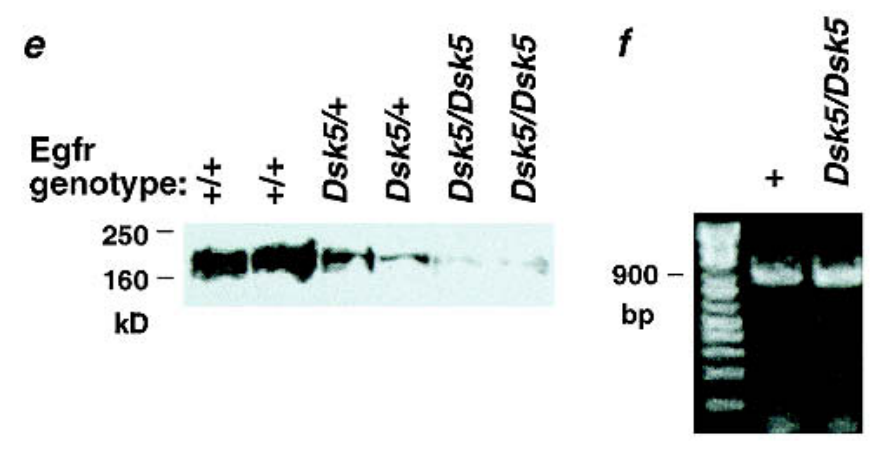

$g$

Egfr genotype: $\quad+/+\quad$ Dsk5/+ EGF Rx: - $+\quad+$ $250-$
$160-$
$250-$
$160-$
KD

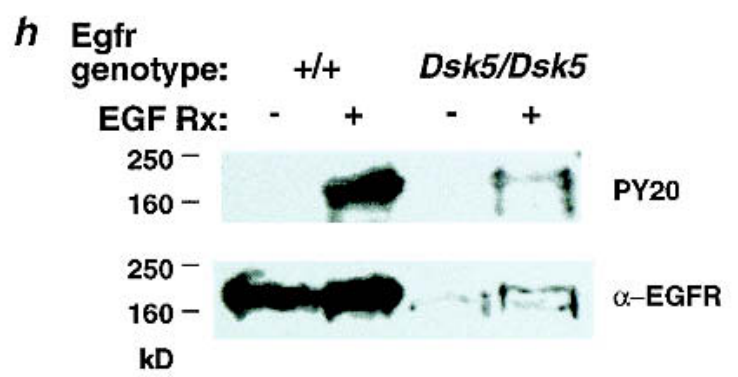

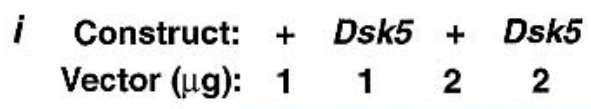

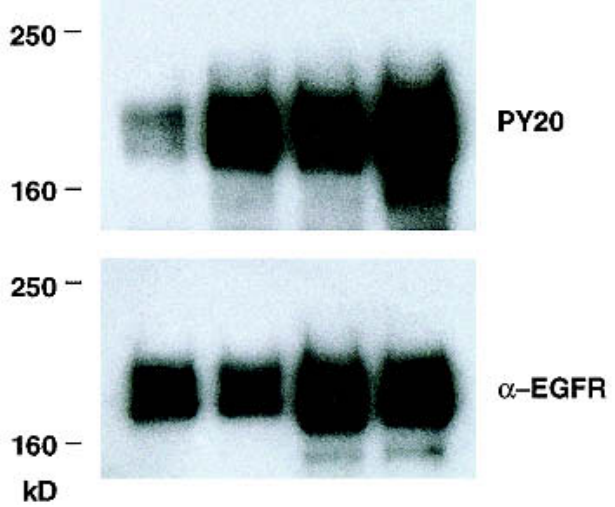

Figure 7. Genetic and biochemical mechanisms of Dsk5 action. (a) Xgal and Egfr immunostaining of a footpad section from a 3-month-old animal carrying the DctLacZ transgene (top); Xgal alone without primary antibody (bottom). (b-d) Footpad phenotypes from 4-month-old +/+ (b), Dsk5/+ $(c)$, and Dsk5/Egfr wa2 $(d)$ littermates shows that a reduction of Egfr signaling caused by the Egfr wa2 allele suppresses the pigmentary phenotype of Dsk5. Results are representative of $14 \mathrm{Dsk} 5 /$ wa2 and 18 Dsk5/+ animals from multiple litters examined at 3-12 mo of age; Egfr wa2/+ animals show no skin (or any other) phenotype. (e) Western blots of liver protein extracts from isogenic $+/+, D s k 5 /+$, or Dsk5/Dsk5 adult animals probed with anti-Egfr. $(f)$ Semiquantitative RT-PCR for an Egfr cDNA fragment prepared from livers of $+/+$ or Dsk5/Dsk5 animals. $(g)$ EGF-induced autophosphorylation of Egfr in vivo. Seven-day-old iosgenic +/+ or Dsk5/+ littermates were injected with EGF as described in Materials and Methods; Western blots were probed sequentially with an antiphosphotyrosine antibody (PY20) and an anti-Egfr antibody, as indicated. (h) Same experiment as in $g$ using 1-month-old isogenic +/+ or Dsk5/Dsk5 animals. Results shown are representative of four normal, four heterozygous, and two homozygous mutant animals. (i) Levels of Egfr and Egfr autophosphorylation for the nonmutant (+) and Dsk5 Leu863Gln Egfr protein as determined by Western blot analysis of extracts from cultured cells transiently transfected with 1 or $2 \mu \mathrm{g}$ of plasmid vector as indicated.

pared the levels of expression and autophosphorylation. Under the conditions used for transient transfection, we found no difference in levels of mutant and normal Egfr protein (Fig. 7i), which demonstrates that the Leu863Gln mutation does not impair Egfr translation, and suggests that the mechanisms responsible for reduced expression 
in vivo (Fig. 7e,g,h) are not represented in cultured cells that transiently express high levels of the receptor. More important, there is a 5- to 10-fold increase in basal levels of autophosphorylation (Fig. 7i).

Taken together with the genetic data (Fig. 7a-c), these observations confirm that increased kinase activity is associated with the Leu863Gln alteration, and help to explain why Dsk5 mutant animals develop hyperkeratosis and epidermal thickening. The reasons why Dsk5 and Egfr ${ }^{w a 2}$ should both cause a wavy coat are not clear, but could represent a general response to alteration of epidermal thickness (in either direction), and/or effects of Egfr signaling on hair keratinocytes.

\section{Molecular characterization of Dccl and Dcc4}

In addition to the 10 dark skin mutants described above, we examined 2 dark coat color mutants, Dcc1 and Dcc4, generated during the same screen. Both the genetic map location and phenotype of Dcc1 suggested it was an allele of Ragged, a classical mouse mutation shown recently (Pennisi et al. 2000) to be caused by mutations in the Sry-related transcription factor Sox18. Dcc1 heterozygotes show reduced agouti banding on dorsal hairs, whereas homozygotes showed sparse hair growth and a complete absence of yellow pigment on the trunk (Fig. 8a-c). PCR amplification of genomic DNA from Dcc1 homozygous animals revealed a nonsense mutation, Leu220ter, in the transactivation domain (Fig. 8d). Three other naturally occurring alleles of Sox18 have been de- scribed with similar phenotypes; all are frameshift mutations that occur within seven codons of the Dcc1 mutation (Downes and Koopman 2001).

Dcc4 homozygotes have completely black hair, similar to the phenotype of pigment type-switching mutations such as Agouti, Atrn, or Mc1r. Complementation crosses suggested that Dcc4 was an allele of Agouti, and in PCR-amplified genomic DNA from Dcc4 homozygous animals, we identified a missense alteration predicted to cause a Met1Leu substitution at the translational initiation site. The phenotype of Dcc4 homozygous animals is similar to amorphic Agouti alleles, and suggests that the Met1Leu mutation completely blocks translation of a functional protein.

\section{Discussion}

Visible phenotypes are a mainstay of mutagenesis experiments in most model organisms; of $\sim 400$ mutations identified in the screen that gave rise to the mutants described here (Hrabé de Angelis et al. 2000), 10\% affected the hair or skin. Both of the Dcc mutants we examined represent new alleles of genes known previously as coat color mutations, but the 10 Dsk mutants represent genes (Dsk2, Dsk5) or genetic map locations (Dsk1, Dsk3, Dsk4, Dsk6, Dsk7, Dsk8, Dsk9, Dsk10) not implicated previously in the pigmentary system (Table 1). Our results demonstrate that the pathogenesis of dark skin in mice can be separated into several genetic processes, each represented by multiple mutations, and that
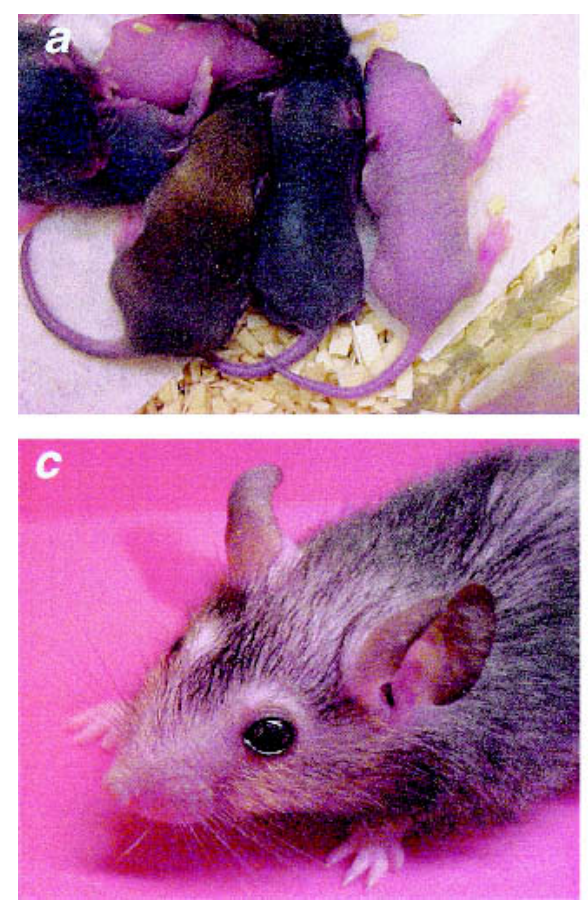

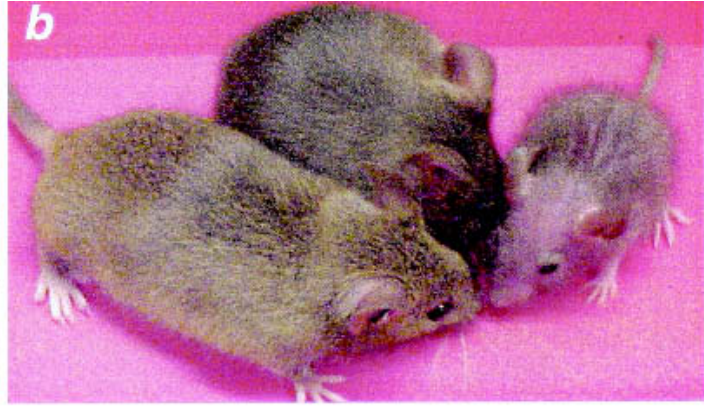

\section{d Sox18}

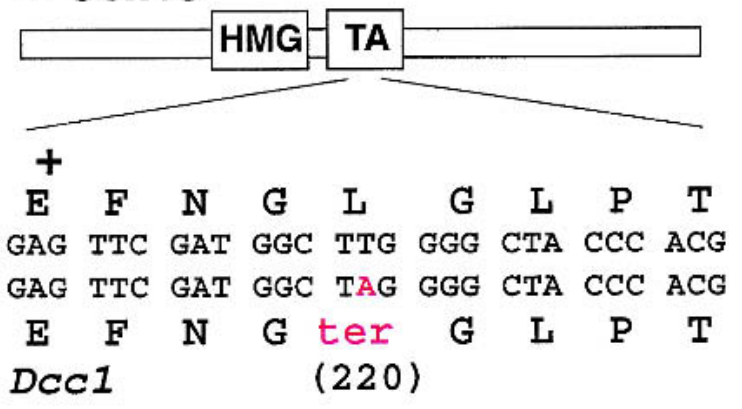

Figure 8. Phenotypic and molecular characterization of $D c c 1$. $(a-c) \mathrm{C} 3 \mathrm{HeB} / \mathrm{Fe} J-D c c 1 /+$ intercross progeny at $1 \mathrm{wk}(a), 3 \mathrm{wk}(b)$, and $3 \mathrm{mo}(c)$ of age. For $a$ and $b$, the genotypes, left to right, are $+/+, D c c 1 /+$, and $D c c 1 / D c c 1$. Heterozygous mutants exhibit a moderately darkened coat and homozygous mutants exhibit almost complete darkening (yellow pigment is preserved in the whiskers) and sparse hair growth. (d) A T-to-A transversion in genomic DNA of Dcc1 mutant animals predicts a nonsense mutation in the transactivation domain of the protein. 
molecular identification of these mutations can provide insight into basic aspects of developmental biology and models for human disease.

\section{Development and pathophysiology of dark skin}

Skin pigmentation in hairy regions of the mouse is most apparent in the first few weeks of life, and is brought about by epidermal melanocytes, large dendritic cells that synthesize and transfer melanin-containing granules to surrounding keratinocytes (Quevedo and Holstein 1998). These epidermal melanocytes differentiate from so-called melanoblasts, small spindle-shaped cells committed to the pigment cell lineage that do not yet actively synthesize melanin, and have migrated extensively, first from the neural crest, and later through dermal mesenchyme (Fig. 1a; Mackenzie et al. 1997; Kunisada et al. 2000; Yoshida et al. 2001; Nishimura et al. 2002). Thus, two major characteristics of the class I mutations Dsk1, Dsk7, and Dsk10-accumulation of excess melanin in the dermis rather than the epidermis, and appearance of dark skin by 2-3 d of age before hair follicle development is complete-indicate that these mutations act relatively early in skin development, at a stage when dermal melanoblasts normally choose between alternative fates, differentiation into dermal melanocytes or continued migration across the dermal-epidermal junction (Table 1; Fig. 1b). The underlying defect in Dsk1,Dsk7, and Dsk10 could bias this choice, causing an increased number of dermal melanocytes and a decreased number of migrating melanoblasts. In the epidermis, however, interfollicular pigmentation is normal, and intrafollicular pigmentation, that is, hair color, is slightly increased. Thus, a more likely explanation for the underlying defect in Dsk1,Dsk7, and Dsk10 is an overall increase of pigment cell precursors in all skin compartments, but whose manifestations are apparent mainly in the dermis and the intrafollicular epidermis due to compensation by a postnatal mechanism that actively removes pigment cells from the epidermis. A developmental mechanism that actively eliminates melanocytes from the interfollicular epidermis helps to explain why skin pigmentation in hairy regions of mice is evident only in the first few weeks of age.

The few regions of the body in which normal skin pigmentation is obvious in adult mice-tails, ears, and footpads-are characterized by sparse or absent hairs and large numbers of dermal melanocytes, and these regions are prominently affected by Dsk1, Dsk7, and Dsk10. A likely human counterpart is the "Mongolian spot" (Kikuchi and Inoue 1980; Cordova 1981; Kikuchi 1989), a localized accumulation of dermal melanocytes at birth that gradually recedes with age and exhibits a bluishgray appearance, similar to what we observe in the footpads of Dsk1, Dsk7, and Dsk10 mutant animals. The molecular pathogenesis of Mongolian spots is obscure; they are benign lesions that have not been described as a Mendelian trait, but are clearly subject to genetic influences; reported in $1 \%-15 \%$ of Caucasians, $50 \%-90 \%$ of Africans or African-Americans, and $>80 \%$ of Asians.
Identification of the molecular lesions responsible for Dsk1, Dsk7, or Dsk10 could help explain why dermal melanocytes accumulate in this common human condition, why their incidence varies among different ethnic groups, and why there is a correlation among different ethnic groups in the incidence of Mongolian spots and dark hair.

Accumulation of excess melanin in the class II mutations Dsk3, Dsk4,Dsk6, and Dsk8 occurs in the epidermis and is not apparent until 2-3 wk of age, after hair follicle development is complete (Table 1). Because none of these mutations affect hair color, the underlying defect must be limited to the transition between epidermal melanoblast and epidermal melanocyte (Fig. 1b), and could involve either an increase in melanocyte number, or an increase in the production and transfer of melanin to surrounding keratinocytes (Table 1; Fig. 1b). The latter class is particularly interesting from the perspective of human genetics, as normal variation in human skin color is mediated by changes in melanocyte activity rather than melanocyte number (Toda et al. 1972; Quevedo et al. 1975; Quevedo and Holstein 1998). Beside rare mutations that cause oculocutaneous albinism, the only human skin color gene identified to date is the melanocortin 1 receptor, in which loss-of-function variants cause fair skin and red hair (Rees et al. 1999; Sturm et al. 2001). Mc1r variation, however, accounts for a small fraction of skin color variation in human populations; in particular, little is known about the genetic basis for skin color that correlates with equatorial proximity of ancestral human populations, or how genes might control skin color independent of hair color (Robins 1991; Jablonski and Chaplin 2000). The exact molecular lesions responsible for Dsk3,Dsk4,Dsk6, and Dsk8 are unlikely to occur as human polymorphisms, because homozygotes are lethal. Nonetheless, identifying the pathways affected by Dsk3, Dsk4, Dsk6, and Dsk8 could provide insight into mechanisms that control normal variation in human skin color.

\section{Epidermal thickening, melanocytosis, and Egfr signaling}

Dsk2 and Dsk 5 both cause epidermal thickening and an increased number of epidermal melanocytes, yet the primary cell biologic abnormalities, keratinocyte fragility, and increased Egfr signaling, respectively, are very different. For both mutants, epidermal thickening is apparent 3-6 wk before dark skin, which points to an underlying mechanism in which the release of one or more paracrine factors from proliferating basal keratinocytes will stimulate secondary proliferation of adjacent pigment cells. Proliferation of basal keratinocytes in Dsk2 mutant animals is itself secondary to a problem in suprabasal keratinocytes, as both the expression of Krt2e, and the epidermal cytolysis in Dsk2 mutant animals occur in the upper spinous layer. Hyperpigmentation is frequently seen in human keratin disorders, not only icthyosis bullosa of Siemens (KRT2E), but also in epidermolytic hyperkeratosis caused by the spinous layer keratins KRT1 or KRT10. Finally, basal cell carcinoma in certain ethnic groups is almost always accompanied by 
epidermal melanocytosis (Maloney et al. 1992; Kikuchi et al. 1996), and lentigenes (benign freckle-like spots that occur in non sun-exposed areas) are associated with increased numbers of melanocytes and increased keratinocyte proliferation (Lever and Schaumburg-Lever 1983). Thus, epidermal melanocytosis may be a general consequence of genetic or environmental lesions that cause increased keratinocyte proliferation.

Phenotypic abnormalities in Dsk2 mutant animals are limited to the ears, tail, and footpads, and correlate with the expression pattern of Krt2e, specific for these same body regions (Herzog et al. 1994). In contrast, phenotypic specificity in Dsk5 mutant animals must be explained by sensitivity of the pigmentary system to slight perturbations in Egfr signaling, because this pathway is used in a wide variety of tissues and developmental stages. Although Leu 863 is conserved in all closely related tyrosine kinases, a Gln occupies this position in phosphorylase kinase $\gamma$, a serine/theonine kinase that, like the Egfr, is not phosphorylated within the activation loop (Owen et al. 1995; Johnson et al. 1996). Thus, the Leu863Gln substitution is unlikely to cause a substantial alteration in conformation of the Egfr activation loop, but could influence its interaction with the catalysis loop or ATP binding. In either case, increased Egfr kinase activity can account not only for epidermal thickening and hyperkeratosis, but also for the reduction in steady-state endogenous Egfr levels, as Egfr activation is directly coupled to internalization and receptor turnover (Schlessinger 1986; Felder et al. 1992). In fact, steadystate down-regulation of the mutant receptor in vivo probably contributes to the relatively mild whole-animal phenotype, because a 5- to 10-fold increase in basal Egfr signaling, as we observed in transiently transfected cells, should have profound effects in several different organ systems. Genetic or environmental perturbations that interfere with receptor down-regulation may uncover more dramatic phenotypes in Dsk5 mutant animals, and provide useful models for studying tumor progression and/or treatment that depends on Egfr signaling.

\section{Candidate genes and candidate phenotypes}

The role of forward genetics in the post-genome era is not yet clear, in part because strategies for obtaining genotype-phenotype correlations based on knockout or association-based approaches are potentially more efficient than positional cloning (Grupe et al. 2001; Mitchell et al. 2001). Our results underscore the utility of focusing on a specific biological process using a phenotype-driven approach; most of the mutations we identified would likely have been overlooked in cursory screens, and a connection between melanocytosis and keratinocyte fragility or Egfr signaling would likely not have been made in a sequence-driven screen. In addition, phenotypic characterization of Dsk1, Dsk3, Dsk4, Dsk6, Dsk7, Dsk8, Dsk9, and $D s k 10$ has revealed distinct genetic steps in a developmental pathway for dark skin; although the genes have not yet been cloned, this serves as a reminder that analysis of mutant phenotypes can provide information about a biological process as the molecular players are being defined.

In the case of Dcc1, Dcc4, Dsk2, and Dsk5, likely positional candidates were easily identified with a lowresolution $(>5 \mathrm{cM})$ genetic map. The optimal map resolution for efficient identification of the remaining Dsk mutations is not yet clear, but as genomic sequence becomes more densely annotated, candidate genes can be more accurately prioritized within a defined physical region, and positional cloning of mouse genes will become more routine. Expansion of the Dsk screen will also increase the efficiency of molecular identification by generating multiple alleles and by clarifying developmental and cell biologic pathways that help to refine the selection of candidate genes. Beside probable allelism be tween Dsk6 and Dsk8, and between Dsk1 and Dsk10, Dsk4 maps to the same region as a mutation identified in the Harwell screen (Nolan et al. 2000), Dark footpads 2 (Dfp2). Thus, 11 dominant dark skin mutants likely map to 8 genetic loci, suggesting that saturation of this screen is feasible.

Expansion of the Dsk screen will allow us to focus on specific phenotypes that address additional components of the dark skin pathway. For example, during the transition from dermis to epidermis, pigment cells switch their pattern of cadherin expression from $\mathrm{N}$ - to E-cadherin; intrafollicular melanocytes that populate adult hair follicles acquire expression of P-cadherin, whereas melanocytes that disappear from the interfollicular epidermis do not (Nishimura et al. 1999; Jouneau et al. 2000). Little is known about the mechanism that normally eliminates melanocytes from the interfollicular epidermis; however, mutations that impair this pathway should be recognized by the appearance of dark skin in hair-bearing regions, and might be anticipated to impinge on or interact with Kit signaling, as transgenic expression of $M g f$ in basal keratinocytes causes expansion and promotes survival of interfollicular melanocytes (Kunisada et al. 1998; Nishimura et al. 2002). Like the Dsk mutations described here, this phenotype may not be immediately apparent to casual observation, but should be easy to detect in a directed screen. Similarly, mutations that simultaneously increase one pigment cell population while decreasing another, that is, dermal melanocytosis associated with hair color dilution, might identify genes that impair the ability of dermal melanoblasts to switch their pattern of cadherin expression and migrate across the dermal-epidermal junction.

Unlike hair color variants, Dsk mutations are not "classical" in the sense of having been collected and stored by mouse fanciers and large research colonies over the last century. Nonetheless, like coat color, our results indicate that differences in mouse skin color can reflect subtle alterations in gene activity or gene dosage, and suggest strategies for how mutagenesis screens might be focused on specific biological questions using pigmentation as an indicator (Tsai et al. 2002). The mutations described here were detected in a dominant screen, in which gain-of-function alterations such as the Egfr Leu863Gln substitution in Dsk5 reveal a positive regulator of pigment cell development or activity. Although 
the logistics of a dominant screen are straightforward, the ability to detect loss-of-function alterations is limited to the small fraction of genes that are haploinsufficient; loss-of-function mutations in Krt2e, Egfr, and Sox18 have, or would likely have escaped detection in the heterozygous state. Alternative strategies to recover loss-of-function mutations use sensitized screens, or recessive screens in the presence of large deficiencies or balancer chromosomes (Frankel 2000; Justice 2000). Availability of loss-of-function mutations that cause dark skin will likely reveal negative regulators of pigment cell development, and, therefore, provide information complementary to the studies described here.

\section{Materials and methods}

\section{Mouse genetics}

In the initial mutagenesis and screening program at the GSF (http://www.gsf.de/ieg), 14,000 animals were surveyed for dominant mutations on the $\mathrm{C} 3 \mathrm{HeB} / \mathrm{FeJ}$ background. Among 186 mutants, $2 \mathrm{Dcc}$ and 7 Dsk mutants were identified; in screening an additional 10,000 animals, 5 more Dsk mutants were recovered, including 3 described here. Except for Dcc4, all mutants were maintained on the $\mathrm{C} 3 \mathrm{HeB} / \mathrm{FeJ}$ background. Dcc4 was identified originally as a dominant mutation but has been maintained as a homozygous strain, $\mathrm{C} 3 \mathrm{HeB} / \mathrm{FeJ}-D c c 4 / D c c 4$, for $>15$ generations. Back-crosses of Dcc4/Dcc4 mice to $\mathrm{C} 3 \mathrm{HeB} / \mathrm{FeJ}$ animals reveal that the coat color phenotype is now fully recessive, which suggests that the original heterozygous phenotype depended on the presence of an unlinked modifier that is no longer present. The DctLacZ reporter transgene was constructed by Ian Jackson and colleagues (Mackenzie et al. 1997), and obtained with his permission from Myung Shin on a mixed background (CBA and C57BL/6J). For genetic interaction studies of Dsk5, B6EiC3H-Egfr ${ }^{\text {wa2 }} / W n t 3 a^{v t}$ animals were obtained from The Jackson Laboratory.

For genetic mapping of Dsk1-Dsk9, we used a pooling strategy, in which genomic DNA samples from 8-20 mutant backcross progeny $[(\mathrm{C} 3 \mathrm{HeB} / \mathrm{Fe}+/-\times \mathrm{C} 57 \mathrm{BL} / 6 \mathrm{~J}) \mathrm{F} 1 \times \mathrm{C} 3 \mathrm{H} / \mathrm{He}]$ were compared with a pool of nonmutant back-cross progeny using a genome-wide panel of simple sequence length polymorphism (SSLP) markers, whose identities are available on request. Potential linkage was verified with individual animals, and at least 100 back-cross progeny were scored for each mutation. Flanking markers for each mutation are: D19Mit109-Dsk1-D19Mit128; D15Mit42-Dsk2-D15Mit246; D7Mit191-Dsk3-D7Mit294; D4Mit149-Dsk4-D4Mit235; D11Mit2-Dsk5-D11Mit294; D3Mit110-Dsk6-D3Mit258; D10Mit115-Dsk7-D10Mit261; D3Mit110-Dsk8-D3Mit258; D11Mit320-Dsk9-D11Mit258; D19Mit56-Dsk10-D19Mit111.

We determined the homozygous phenotype for Dsk1-Dsk9 by examining $(\mathrm{C} 3 \mathrm{HeB} / \mathrm{Fe}-\mathrm{Dsk} /+\times \mathrm{C} 57 \mathrm{BL} / 6 \mathrm{~J}) \mathrm{F} 1$ intercross progeny using molecular markers informative for the Dsk genetic interval; at least 50 F2 progeny were examined for each mutation (Table 1). All of the mutations exhibited an increase in variability of expression on the mixed background used for mapping; however, all were fully penetrant except for Dsk9, for which homozygous lethality in F2 intercross animals was used to determine a more accurate map position.

\section{Histology}

For each Dsk mutant strain, skin from 3-4-week-old mutant and nonmutant littermates was removed from the footpads, fixed in $4 \%$ paraformaldehyde, and embedded in paraffin; 7-um sections from all regions (volar pads and intervolar scales) were stained with hematoxylin and eosin, and examined by light microscopy. Footpads from at least three animals were sectioned for each mutant. For lacZ staining, Dsk2/+ or Dsk5/+ mutants were crossed to the animals heterozygous for the DctLacZ re porter transgene; skin samples from transgenic Dsk mutant and nonmutant littermates were stained in parallel with Xgal and eo$\sin$ as described (Mackenzie et al. 1997). At least 40 sections were examined from 2 sets of mutant and nonmutant littermates.

\section{Molecular genetics}

For Krt1, Krt2e, Agouti, and Sox18, genomic DNA prepared from homozygous mutant and nonmutant tails was sequenced directly after PCR amplification. For Egfr, PCR-amplified cDNA was prepared from liver RNA of homozygous mutant and nonmutant animals, cloned into pCR-TOPO (Invitrogen), and sequenced using vector primers. All mutations were verified by examining genomic DNA in independent amplification reactions from three or more mutant animals and comparison with genomic DNA from the nonmutant strain of origin; oligonucleotide primer sequences are available on request. No differences between mutant and nonmutant sequences were detected other than the variants presented in the Results section. Causative lesions for Krt2e, Egfr, and Sox18 are presented in Figures 4, 6, and 8, respectively; for Agouti (Dcc4), the causative molecular lesion is an A-to-T transversion at the first position of the translational initiation codon.

\section{Dsk5 and Egfr}

For interaction studies between $D s k 5$ and $E g f r^{w a 2}$, progeny from a $\mathrm{C} 3 \mathrm{HeB} / \mathrm{FeJ}-D s k 5 /+\times \mathrm{B} 6 \mathrm{EiC} 3 \mathrm{H}-E g f r^{\text {wa2 }} / W n t 3 a^{\text {vt }}$ cross were examined and scored blindly for the presence and extent of footpad pigmentation. Presence of the Dsk5 mutation was determined by AluI digestion of PCR amplified (5'-AGATGGTT CACTCCCTCACG-3' and 5'-ATGCTTCCTGATCTACTCCC $3^{\prime}$ ) genomic DNA; the Dsk5 mutation introduces an AluI restriction enzyme site, and thus yields two fragments of 70 and $150 \mathrm{bp}$. The presence of the Egfr-wa2 allele was determined by FokI digestion of PCR-amplified genomic DNA (http://jaxmice.jax.org/html/pricelist/wa2.pdf).

For Egfr immunohistochemistry, footpads and tails from 3-month-old animals carrying the DctLacZ transgene were fixed and stained for $l a c Z$ as described above. Ten-micrometer sections were cleared in Xylene, rehydrated in an ethanol series, then treated for $10 \mathrm{~min}$ with $3 \%$ hydrogen peroxide, and washed in PBS. Slides were blocked with $1.5 \%$ normal goat serum, then incubated with a 1:500 dilution of Egfr antibody (sc-03, Santa Cruz Biotechnology) overnight at $4^{\circ} \mathrm{C}$. The next day, slides were incubated with a 1:750 dilution of biotin-conjugated goat antirabbit antibody for $1 \mathrm{~h}$ at room temperature, followed by detection using the Vectastain Elite ABC kit (Vector laboratories). For the negative control, slides were processed without primary antibody.

For Egfr detection in tissues, F2 progeny from a C3HeB/FeJDsk5/+ intercross were euthanized, genotyped as described above, and livers from +/+, Dsk5/+, and Dsk5/Dsk5 animals were dissected and homogenized on ice in $20 \mathrm{mM}$ Hepes $(\mathrm{pH}$ 7.4), 1\% Triton X-100, 2 mM EDTA, 2 mM EGTA, $500 \mu \mathrm{m}$ $\mathrm{Na} 3 \mathrm{VO} 4,50 \mu \mathrm{M}$ Na2Mo4O4 and a protease inhibitor cocktail (1× Complete, Roche Molecular Biochemicals) as described in Donaldson and Cohen (1992). Homogenates were centrifuged at $14,000 \mathrm{~g}$ in the cold room for $5 \mathrm{~min}$, and the supernatants retained as total cell lysates. Protein concentrations were determined using Coomassie Plus Reagent (Pierce Biochemicals), and 
$150 \mu \mathrm{g}$ of total protein per sample was analyzed by Western blotting. Protein blots were incubated with anti-EGFR (sc-03, Santa Cruz Biotechnology) or anti-phosphotyrosine antibody (PY20, Santa Cruz Biotechnology), and detected using chemiluminescence (ECL, Amersham).

For studies with administration of EGF or phosphatase inhibitors, animals genotyped as described above were injected subcutaneously with $100 \mu \mathrm{L}$ of PBS, with $0.1-5 \mu \mathrm{g} \mathrm{EGF/g} \mathrm{body}$ weight dissolved in PBS, or with $10 \mu \mathrm{L} / \mathrm{g}$ of body weight of a phosphatase inhibitor solution (5 mM Na3VO4, $50 \mathrm{mM} \mathrm{H} 2 \mathrm{O} 2)$ as described in Ruff et al. (1997). Twenty minutes after injection, animals were euthanized, livers dissected, and total cell lysates obtained as described above.

For the cell culture studies, the Leu863Gln mutation was introduced into an Egfr expression vector (pcDNA3.1, Invitrogen) by site-directed mutagenesis (GeneEditor, Promega) and the entire coding region verified by sequence analysis. COS cells at $50 \%$ confluency in a 6 -well plate were transfected (FuGENE, Roche Molecular Biochemicals) with either 1 or $2 \mu \mathrm{g}$ of normal or Egfr expression vector; for the $1 \mu \mathrm{g}$ transfections, an additional $1 \mu \mathrm{g}$ of GFP expression vector was added to verify and compare transfection efficiency for different wells. After $18 \mathrm{~h}$, transfected cells were washed twice with cold PBS, and cell lysates prepared by incubation in $100 \mu \mathrm{L}$ of lysis solution $(20$ $\mathrm{mM}$ HEPES at $\mathrm{pH} 7.4,150 \mathrm{mM} \mathrm{NaCl}, 10 \%$ glycerol, $1 \%$ Triton $\mathrm{X}-100,1 \mathrm{mM}$ PMSF, $10 \mu \mathrm{g} / \mathrm{mL}$ leupeptin, $10 \mu \mathrm{g} / \mathrm{mL}$ aprotinin, 1 $\mathrm{mM}$ sodium vanadate, $10 \mathrm{mM} \beta$-glycerophosphate) at $4^{\circ} \mathrm{C}$ for 15 $\min$. The debris was cleared by centrifugation and protein concentration was measured using a Bradford assay (BioRad).An equal amount $(10 \mu \mathrm{g})$ of protein was separated on $6 \%$ SDSPAGE, transferred to PVDF membranes, and then treated as described above.

\section{Acknowledgments}

We thank Joe Lee for help with Sox18 sequencing, Hermie Manuel for preparing tail DNA, and the core facility of the GSF ENU mutagenesis screen for the care and organization of animal resources. We thank Ian Jackson and Myung Shin for the DctLacZ mice. The mutations Dsk2, Dsk3, Dsk5, and Dcc1 were kindly provided by Ingenium Pharmaceuticals. K.R.F. was supported by a National Research Service Award from the National Institutes of Health (GM20733), and C.D.v.R. was supported by a training grant from the National Institutes of Health (CA09151). Part of this work was supported by a grant from the German Human Genome Project (DHHP) and the National Genome Research Network (NGFN) to M.H.d.A. G.S.B. is an Associate Investigator of the Howard Hughes Medical Institute.

The publication costs of this article were defrayed in part by payment of page charges. This article must therefore be hereby marked "advertisement" in accordance with 18 USC section 1734 solely to indicate this fact.

\section{References}

Arin, M.J. and Roop, D.R. 2001. Disease model: Heritable skin blistering. Trends Mol. Med. 7: 422-424.

Balling, R. 2001. ENU mutagenesis: Analyzing gene function in mice. Annu. Rev. Genomics Hum. Genet. 2: 463-492.

Bedell, M.A., Jenkins, N.A., and Copeland, N.G. 1997. Mouse models of human disease. Part I: Techniques and resources for genetic analysis in mice. Genes \& Dev. 11: 1-10.

Broome Powell, M., Gause, P.R., Hyman, P., Gregus, J., Lluria-Prevatt, M., Nagle, R., and Bowden, G.T. 1999. Induction of melanoma in TPras transgenic mice. Carcinogenesis 20: 1747-1753.

Budd, P.S., Antoniou, J., Mellor, A.L., and Jackson, I.J. 1997.
Sooty foot, a novel mouse mutation that affects the pigmentation of exposed skin, but not hair, maps to chromosome 2 . Mamm. Gen. 8: 631-635.

Cordova, A. 1981. The Mongolian spot: A study of ethnic differences and a literature review. Clin. Pediatr. 20: 714-719.

Donaldson, R.W. and Cohen, S. 1992. Epidermal growth factor stimulates tyrosine phosphorylation in the neonatal mouse: Association of a $\mathrm{M}(\mathrm{r}) 55,000$ substrate with the receptor. Proc. Natl. Acad. Sci. 89: 8477-8481.

Downes, M. and Koopman, P. 2001. SOX18 and the transcriptional regulation of blood vessel development. Trends Cardiovasc. Med. 11: 318-324.

Felder, S., LaVin, J., Ullrich, A., and Schlessinger, J. 1992. Kinetics of binding, endocytosis, and recycling of EGF receptor mutants. J. Cell. Biol. 117: 203-212.

Fowler, K.J., Walker, F., Alexander, W., Hibbs, M.L., Nice, E.C., Bohmer, R.M., Mann, G.B., Thumwood, C., Maglitto, R., Danks, J.A., et al. 1995. A mutation in the epidermal growth factor receptor in waved-2 mice has a profound effect on receptor biochemistry that results in impaired lactation. Proc. Natl. Acad. Sci. 92: 1465-1469.

Frankel, W.N. 2000. Mouse mutagenesis is 'in'. Sharing experience and resources in large-scale functional genomics: $\mathrm{Mu}-$ tagenesis of the mouse genome, Georgia Genetics Symposium II, Athens, Georgia, 6-9, September 2000. Trends Genet. 16: 540

Fuchs, E. 1996. The cytoskeleton and disease: Genetic disorders of intermediate filaments. Annu. Rev. Genet. 30: 197-231.

Gordon-Thomson, C., Mason, R.S., and Moore, G.P. 2001. Regulation of epidermal growth factor receptor expression in human melanocytes. Exp. Dermatol. 10: 321-328.

Grupe, A., Germer, S., Usuka, J., Aud, D., Belknap, J.K., Klein, R.F., Ahluwalia, M.K., Higuchi, R., and Peltz, G. 2001. In silico mapping of complex disease-related traits in mice. Science 292: 1915-1918.

Herzog, F., Winter, H., and Schweizer, J. 1994. The large type II $70-\mathrm{kDa}$ keratin of mouse epidermis is the ortholog of human keratin K2e. J. Invest. Dermatol. 102: 165-170.

Hirobe, T. 1988. Developmental changes of the proliferative response of mouse epidermal melanocytes to skin wounding. Development 102: 567-574.

Hrabé de Angelis, M.H., Flaswinkel, H., Fuchs, H., Rathkolb, B., Soewarto, D., Marschall, S., Heffner, S., Pargent, W., Wuensch, K., Jung, M., et al. 2000. Genome-wide, large-scale production of mutant mice by ENU mutagenesis. Nat. Genet. 25: 444-447.

Jablonski, N.G. and Chaplin, G. 2000. The evolution of human skin coloration. J. Hum. Evol. 39: 57-106.

Jackson, I.J. 1997. Homologous pigmentation mutations in human, mouse and other model organisms. Hum. Mol. Genet. 6: $1613-1624$.

Johnson, L.N., Noble, M.E., and Owen, D.J. 1996. Active and inactive protein kinases: Structural basis for regulation. Cell 85: 149-158.

Jouneau, A., Yu, Y.Q., Pasdar, M., and Larue, L. 2000. Plasticity of cadherin-catenin expression in the melanocyte lineage. Pigment Cell. Res. 13: 260-272.

Justice, M.J. 2000. Capitalizing on large-scale mouse mutagenesis screens. Nat. Rev. Genet. 1: 109-115.

Justice, M.J., Noveroske, J.K., Weber, J.S., Zheng, B., and Bradley, A. 1999. Mouse ENU mutagenesis. Hum. Mol. Genet. 8: 1955-1963.

Kikuchi, I. 1989. The biological significance of the Mongolian spot. Int. J. Dermatol. 28: 513-514.

Kikuchi, I. and Inoue, S. 1980. Natural history of the Mongolian spot. J. Dermatol. 7: 449-450.

Kikuchi, A., Shimizu, H., and Nishikawa, T. 1996. Clinical histopathological characteristics of basal cell carcinoma in Japanese patients. Arch. Dermatol. 132: 320-324. 
Kunisada, T., Yoshida, H., Yamazaki, H., Miyamoto, A., Hemmi, H., Nishimura, E., Shultz, L.D., Nishikawa, S., and Hayashi, S. 1998. Transgene expression of steel factor in the basal layer of epidermis promotes survival, proliferation, differentiation and migration of melanocyte precursors. Development 125: 2915-2923.

Kunisada, T., Yamazaki, H., Hirobe, T., Kamei, S., Omoteno, M., Tagaya, H., Hemmi, H., Koshimizu, U., Nakamura, T., and Hayashi, S.I. 2000. Keratinocyte expression of transgenic hepatocyte growth factor affects melanocyte development, leading to dermal melanocytosis. Mech. Dev. 94: 67-78.

Lever, W.F. and Schaumburg-Lever, G. 1983. Histopathology of the skin. Lippincott, Philadelphia, PA.

Luetteke, N.C., Phillips, H.K., Qiu, T.H., Copeland, N.G., Earp, H.S., Jenkins, N.A., and Lee, D.C. 1994. The mouse waved-2 phenotype results from a point mutation in the EGF receptor tyrosine kinase. Genes \& Dev. 8: 399-413.

Mackenzie, M.A., Jordan, S.A., Budd, P.S., and Jackson, I.J. 1997. Activation of the receptor tyrosine kinase Kit is required for the proliferation of melanoblasts in the mouse embryo. Dev. Biol. 192: 99-107.

Maloney, M.E., Jones, D.B., and Sexton, F.M. 1992. Pigmented basal cell carcinoma: investigation of 70 cases. J. Am. Acad. Dermatol. 27: 74-78.

Mann, G.B., Fowler, K.J., Gabriel, A., Nice, E.C., Williams, R.L., and Dunn, A.R. 1993. Mice with a null mutation of the TGF $\alpha$ gene have abnormal skin architecture, wavy hair, and curly whiskers and often develop corneal inflammation. Cell 73: 249-261.

Mattei, S., Colombo, M.P., Melani, C., Silvani, A., Parmiani, G., and Herlyn, M. 1994. Expression of cytokine/growth factors and their receptors in human melanoma and melanocytes. Int. J. Cancer 56: 853-857.

Mitchell, K.J., Pinson, K.I., Kelly, O.G., Brennan, J., Zupicich, J., Scherz, P., Leighton, P.A., Goodrich, L.V., Lu, X., Avery, B.J., et al. 2001. Functional analysis of secreted and transmembrane proteins critical to mouse development. Nat. Genet. 28: 241-249.

Nishimura, E.K., Yoshida, H., Kunisada, T., and Nishikawa, S.I. 1999. Regulation of E- and P-cadherin expression correlated with melanocyte migration and diversification. Dev. Biol. 215: 155-166.

Nishimura, E.K., Jordan, S.A., Oshima, H., Yoshida, H., Osawa, M., Moriyama, M., Jackson, I.J., Barrandon, Y., Miyachi, Y., and Nishikawa, S. 2002. Dominant role of the niche in melanocyte stem-cell fate determination. Nature 416: 854-860.

Nolan, P.M., Peters, J., Strivens, M., Rogers, D., Hagan, J., Spurr, N., Gray, I.C., Vizor, L., Brooker, D., Whitehill, E., et al. 2000. A systematic, genome-wide, phenotype-driven mutagenesis programme for gene function studies in the mouse. Nat. Genet. 25: 440-443.

Owen, D.J., Noble, M.E., Garman, E.F., Papageorgiou, A.C., and Johnson, L.N. 1995. Two structures of the catalytic domain of phosphorylase kinase: An active protein kinase complexed with substrate analogue and product. Structure 3: 467-482.

Pennisi, D., Gardner, J., Chambers, D., Hosking, B., Peters, J., Muscat, G., Abbott, C., and Koopman, P. 2000. Mutations in Sox18 underlie cardiovascular and hair follicle defects in ragged mice. Nat. Genet. 24: 434-437.

Quevedo, W.C. and Holstein, T.J. 1998. General biology of mammalian pigmentation. In The pigmentary system (ed. J.J. Nordlunkd, R.E. Boissy, V.J. Hearing, R.A. King, and J.-P. Ortonne), pp. 43-58. Oxford University Press, New York.

Quevedo, W.C., Fitzpatrick, T.B., Pathak, M.A., and Jimbow, K. 1975. Role of light in human skin color viariation. Am. J. Phys. Anthropol. 43: 393-408.

Rees, J.L., Birch-Machin, M., Flanagan, N., Healy, E., Phillips,
S., and Todd, C. 1999. Genetic studies of the human melanocortin-1 receptor. Ann. NY Acad. Sci. 885: 134-142.

Robins, A.H. 1991. Biological perspectives on human pigmentation. Cambridge University Press, New York.

Rosdahl, I.K. 1979. Local and systemic effects on the epidermal melanocyte population in UV-irradiated mouse skin. J. Invest. Dermatol. 73: 306-309.

Ruff, S.J., Chen, K., and Cohen, S. 1997. Peroxovanadate induces tyrosine phosphorylation of multiple signaling proteins in mouse liver and kidney. J. Biol. Chem. 272: 1263-1267.

Schlessinger, J. 1986. Allosteric regulation of the epidermal growth factor receptor kinase. J. Cell. Biol. 103: 2067-2072.

Shiroishi, T. 2001. A large-scale mouse mutagenesis with a chemical mutagen ENU. Tanpakushitsu Kakusan Koso 46: 2613-2618.

Silvers, W.K. 1979. The coat colors of mice: A model for mammalian gene action and interaction. Springer-Verlag, New York.

Smith, L.T., Underwood, R.A., and McLean, W.H. 1999. Ontogeny and regional variability of keratin $2 \mathrm{e}(\mathrm{K} 2 \mathrm{e})$ in developing human fetal skin: A unique spatial and temporal pattern of keratin expression in development. Br. J. Dermatol. 140: 582-591.

Spritz, R.A. 1999. Multi-organellar disorders of pigmentation: Tied up in traffic. Clin. Genet. 55: 309-317.

Stamos, J., Sliwkowski, M.X., and Eigenbrot, C. 2002. Structure of the EGF receptor kinase domain alone and in complex with a4anilinoquinazoline inhibitor. J. Biol. Chem. 277:46265-46272.

Steijlen, P.M., Perret, C.M., Schuurmans Stekhoven, J.H., Ruiter, D.J., and Happle, R.1990. Ichthyosis bullosa of Siemens: Further delineation of the phenotype. Arch. Dermatol. Res. 282: 1-5.

Sturm, R.A., Teasdale, R.D., and Box, N.F. 2001. Human pigmentation genes: Identification, structure and consequences of polymorphic variation. Gene 277: 49-62.

Thaung, C., West, K., Clark, B.J., McKie, L., Morgan, J.E., Arnold, K., Nolan, P.M., Peters, J., Hunter, A.J., Brown, S.D., et al. 2002. Novel ENU-induced eye mutations in the mouse: Models for human eye disease. Hum. Mol. Genet. 11: 755-767.

Threadgill, D.W., Dlugosz, A.A., Hansen, L.A., Tennenbaum, T., Lichti, U., Yee, D., LaMantia, C., Mourton, T., Herrup, K., Harris, R.C., et al. 1995. Targeted disruption of mouse EGF receptor: effect of genetic background on mutant phenotype. Science 269: 230-234.

Toda, K., Pathak, M.A., Parrish, J.A., Fitzpatrick, T.B., and Quevedo Jr., W.C. 1972. Alteration of racial differences in melanosome distribution in human epidermis after exposure to ultraviolet light. Nat. New Biol. 236: 143-145.

Traupe, H., Kolde, G., Hamm, H., and Happle, R. 1986. Ichthyosis bullosa of Siemens: A unique type of epidermolytic hyperkeratosis. J. Am. Acad. Dermatol. 14: 1000-1005.

Tsai, T.F., Chen, K.S., Weber, J.S., Justice, M.J., and Beaudet, A.L. 2002. Evidence for translational regulation of the imprinted Snurf-Snrpn locus in mice. Hum. Mol. Genet. 11: 1659-1668.

Vassar, R. and Fuchs, E. 1991. Transgenic mice provide new insights into the role of TGF- $\alpha$ during epidermal development and differentiation. Genes \& Dev. 5: 714-727.

Yang, J.M., Lee, S., Bang, H.D., Kim, W.S., Lee, E.S., and Steinert, P.M. 1997. A novel threonine to proline mutation at the end of $2 \mathrm{~B}$ rod domain in the keratin 2e chain in ichthyosis bullosa of Siemens. J. Invest. Dermatol. 109: 116-118.

Yoshida, H., Kunisada, T., Kusakabe, M., Nishikawa, S., and Nishikawa, S.I. 1996. Distinct stages of melanocyte differentiation revealed by anlaysis of nonuniform pigmentation patterns. Development 122: 1207-1214.

Yoshida, H., Kunisada, T., Grimm, T., Nishimura, E.K., Nishioka, E., and Nishikawa, S.I. 2001. Review: Melanocyte migration and survival controlled by SCF/c-kit expression. $J$. Investig. Dermatol. Symp. Proc. 6: 1-5. 


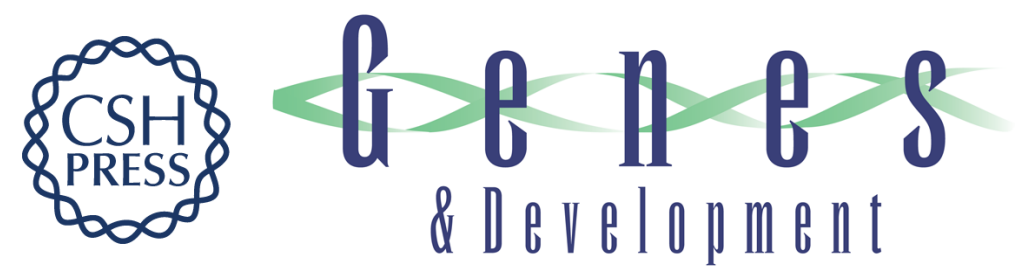

\section{Genetics of dark skin in mice}

Karen R. Fitch, Kelly A. McGowan, Catherine D. van Raamsdonk, et al.

Genes Dev. 2003, 17:

Access the most recent version at doi:10.1101/gad.1023703

References This article cites 58 articles, 14 of which can be accessed free at: http://genesdev.cshlp.org/content/17/2/214.full.html\#ref-list-1

License

Email Alerting Receive free email alerts when new articles cite this article - sign up in the box at the top Service right corner of the article or click here.

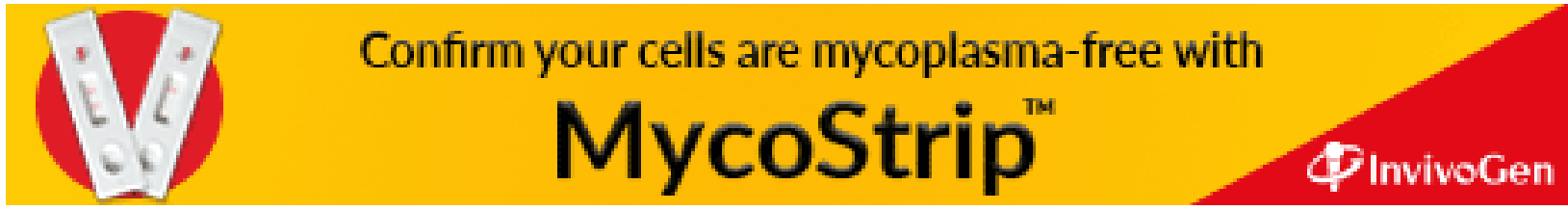

